Article

\title{
Comparative Transcriptome Profiling of Skeletal Muscle from Black Muscovy Duck at Different Growth Stages Using RNA-seq
}

\author{
Zhigang $\mathrm{Hu} \unrhd^{\circledR}$, Junting Cao, Guangyu Liu, Huilin Zhang and Xiaolin Liu* \\ College of Animal Science and Technology, Northwest A\&F University, Yangling 712100, China; \\ huzhigang2017060163@nwafu.edu.cn (Z.H.); fightingcaoting@nwafu.edu.cn (J.C.); \\ guangyuliu@nwafu.edu.cn (G.L.); zhhl7461@nwsuaf.edu.cn (H.Z.) \\ * Correspondence: liuxiaolin@nwsuaf.edu.cn
}

Received: 26 September 2020; Accepted: 16 October 2020; Published: 20 October 2020

check for updates

\begin{abstract}
In China, the production for duck meat is second only to that of chicken, and the demand for duck meat is also increasing. However, there is still unclear on the internal mechanism of regulating skeletal muscle growth and development in duck. This study aimed to identity candidate genes related to growth of duck skeletal muscle and explore the potential regulatory mechanism. RNA-seq technology was used to compare the transcriptome of skeletal muscles in black Muscovy ducks at different developmental stages (day 17, 21, 27, 31, and 34 of embryos and postnatal 6-month-olds). The SNPs and InDels of black Muscovy ducks at different growth stages were mainly in "INTRON", "SYNONYMOUS_CODING", "UTR_3_PRIME", and "DOWNSTREAM". The average number of AS in each sample was 37,267, mainly concentrated in TSS and TTS. Besides, a total of 19 to 5377 DEGs were detected in each pairwise comparison. Functional analysis showed that the DEGs were mainly involved in the processes of cell growth, muscle development, and cellular activities (junction, migration, assembly, differentiation, and proliferation). Many of DEGs were well known to be related to growth of skeletal muscle in black Muscovy duck, such as MyoG, FBXO1, $M E F 2 A$, and FoxN2. KEGG pathway analysis identified that the DEGs were significantly enriched in the pathways related to the focal adhesion, MAPK signaling pathway and regulation of the actin cytoskeleton. Some DEGs assigned to these pathways were potential candidate genes inducing the difference in muscle growth among the developmental stages, such as FAF1, RGS8, GRB10, SMYD3, and TNNI2. Our study identified several genes and pathways that may participate in the regulation of skeletal muscle growth in black Muscovy duck. These results should serve as an important resource revealing the molecular basis of muscle growth and development in duck.
\end{abstract}

Keywords: skeletal muscle; transcriptome; gene expression; duck; growth stage

\section{Introduction}

Skeletal muscle is the largest and most important tissue in animals, accounting for about $50 \%$ of body weight [1,2]. It participates in body movement, protection, and metabolic regulation [3]. Because meat yield directly determines the level of economic benefits, the study of skeletal muscle development is important in animal husbandry production. The growth and development of duck skeletal muscle is an essential economic trait, which is determined by genetic, and influenced by nutritional and environmental factors. The development of embryonic skeletal muscle is a tightly regulated process that is critically modulated by genes and related signaling pathways $[4,5]$. During prenatal and very early postnatal development, muscle growth in vertebrates depends on an increasing number of muscle fibers (hyperplasia) [6,7]. After postnatal growth, the increase in skeletal 
muscle is mainly due to muscle hypertrophy, accompanied by the proliferation of satellite cells and then the new myonuclei is incorporated into existing myofibers [8]. Black Muscovy duck, an excellent meat duck breed in China, has the advantages of fast growth and high lean meat rate. Most notably, few studies have investigated the mechanisms regulating growth patterns of skeletal muscle in black Muscovy duck. Since the growth of skeletal muscle is controlled by multiple genes, a more systematic understanding of the genes expressed at different growth stages in black Muscovy duck is needed.

Transcriptome sequencing (RNA-seq) is a technology that analyzing the transcripts by deep sequencing technology, which detects the whole transcriptome at the single nucleotide level [9]. It analyzes the structure and expression level of transcripts, which is an important method of gene expression and transcription analysis [10]. In recent years, RNA-seq has been widely used in study on livestock and poultry transcriptomes. Compared with other gene expression profiling methods, RNA-Seq has advantages in detecting mRNA expression in different tissues or at different developmental stages, which is helpful to reveal new genes and splicing variations [11], as well as the pathways [12]. Several studies at mRNA level have been performed in poultry birds, with the aims to investigate and analyze the genes and pathways that influence the growth and development of skeletal muscle. Xue et al. (2018) compared the mRNA expression of leg muscles of Jinghai Yellow Chickens at early growth stages by RNA-seq, a total of 978 differentially expressed genes (DEGs) were identified, and five significantly enriched pathways were found: EMC-receptor interaction, focal adhesion, tight junction, insulin signaling pathway, and regulation of the actin cytoskeleton [13]. Transcriptome analysis of breast muscle in Commercial Layers of Roman, White Broiler, and Daheng chickens showed that genes related to positive cell proliferation, growth, cell differentiation and developmental processes were more enriched, and the pathways, including ECM-receptor interaction, MAPK signaling pathway and focal adhesion, were the most enriched DEGs [14]. Xu et al. (2017) analyzed the gene expression profiles of Pekin ducks during incubation period, and the results showed that the DEGs related to cell division ( $\mathrm{M}$ phase of mitotic cell cycle, cell division, mitosis, and mitotic prometaphase), and the pathways, including DNA replication, Cell cycle, Gap junction, were significantly enriched at hatched day 19 [15]. Zhu et al. (2017) analyzed potential candidate genes and signaling pathways related to the development of breast muscle during late-term embryonic to neonatal development, a total of 393 DEGs were identified, and the DEGs involved in different metabolism pathways (such as metabolic pathways, citrate cycle, glycine, serine, and threonine metabolism, sulfur metabolism, carbon metabolism, and pyruvate metabolism) [16].

The purpose of this study was to investigate the major DEGs and their expression pathways in skeletal muscle of black Muscovy duck by using RNA-Seq technology and bioinformatic tools. We found the genes and molecular mechanisms involved in this developmental process by carrying out a comprehensive analysis of genes with expression levels that reflected the growth pattern of breast and leg muscles in black Muscovy duck. Our findings are useful for understanding the mechanisms regulating the development of skeletal muscle and the pattern of duck growth.

\section{Materials and Methods}

\subsection{Animal and Muscle Tissue Collection}

One hundred eggs of black Muscovy duck were incubated in a standard incubator after disinfection. A total of 8 eggs were sampled from the day 17 (BE17), day 21 (BE21), day 27 (BE27), day 31 (BE31), and day 34 (BE34) of the incubation period, and the breast and leg muscle were separated for DNA and RNA extraction. DNA of muscle tissue was extracted according to the phenol chloroform protocol. According to the sequence of chromatin helix DNA binding protein 1 (CHD1) gene on sex chromosomes of duck, sex identification primers (gCHD) were used [17] and female embryos were selected as the research objects (Table 1), because the female Muscovy duck accounted for the majority of duck farms due to the reason of laying eggs, and the same gender can avoid the error of sequencing data. Besides, 6-month-old female ducks (BM6), raising under the same environmental conditions and free access 
to feed and water (Table 2), were slaughtered quickly to collect the breast muscle and leg muscle. Muscles were excised and immediately frozen in liquid nitrogen and stored at $-80{ }^{\circ} \mathrm{C}$ until further use. Animal care, slaughter and experimental procedures were approved by Institutional Animal Care and Institutional Ethic Committee of Northwest A\&F University (ethic code: \#0326/2019).

Table 1. qPCR primer sequences of black Muscovy duck.

\begin{tabular}{|c|c|c|c|c|}
\hline Groups & Primer Name & Primer Sequence $\left(5^{\prime}-3^{\prime}\right)$ & Amplicon Size & Regulated \\
\hline \multirow{3}{*}{ BE17B_vs_BE21B } & $\mathrm{gCHD}$ & $\begin{array}{l}\text { F: TGCAGAAGCAATATTACAAGT } \\
\text { R: AATTCATTATCATCTGGTGG }\end{array}$ & $\begin{array}{c}\text { Male: } 467 \mathrm{bp} \\
\text { Female: } 467 \mathrm{bp}, 326 \mathrm{bp}\end{array}$ & \\
\hline & HOXC6 & $\begin{array}{l}\text { F:CCAAAACAGGAACACTTCGCA } \\
\text { R:AAAAGTCGCTCAGCCTGTTCT }\end{array}$ & $167 \mathrm{bp}$ & Down \\
\hline & KIF1A & $\begin{array}{l}\text { F:AAAGGGCTACCTGCACTTCC } \\
\text { R:CTGCACCCACCTTCAGCAT }\end{array}$ & $188 \mathrm{bp}$ & Down \\
\hline \multirow{2}{*}{ BE17B_vs_BE27B } & SOX7 & $\begin{array}{l}\text { F:AGATGGACCGCAACGAAT } \\
\text { R:CAGCAAGGACGGAGATGA }\end{array}$ & $150 \mathrm{bp}$ & Up \\
\hline & GPR37 & $\begin{array}{l}\text { F:CGCCAGTCCTCCTTTTCTGT } \\
\text { R:ATTTCACGACGGATGGTGCT }\end{array}$ & $175 \mathrm{bp}$ & Down \\
\hline \multirow{2}{*}{ BE17B_vs_BE31B } & FUT9 & $\begin{array}{l}\text { F:GACGTACTTGGTCTGGGTCA } \\
\text { R:GCACCCCACCTTACAACCTC }\end{array}$ & $158 \mathrm{bp}$ & Up \\
\hline & POLA1 & $\begin{array}{l}\text { F:CCGCTCAGAAAGGAGGTGATT } \\
\text { R:CTCCCTTTTCAGCCCATCACT }\end{array}$ & $172 \mathrm{bp}$ & Up \\
\hline BE17B_vs_BE34B & $A N L N$ & $\begin{array}{l}\text { F:TTCCAGGACAAGGTTCCTGTT } \\
\text { R:AGTTTATCCGGCCCAAAGGAT }\end{array}$ & $229 \mathrm{bp}$ & Down \\
\hline \multirow[t]{2}{*}{ BE17B_vs_BM6B } & FGF19 & $\begin{array}{l}\text { F: TGTCTTTGCTTGGCGCTACT } \\
\text { R:CAGTGTACGGTGTGGTTGAGT }\end{array}$ & $214 \mathrm{bp}$ & Down \\
\hline & SPIN1 & $\begin{array}{c}\text { F:TCGGATTAGTGATGCCCACC } \\
\text { R:CTGGCCTACTTACTGGAATCGG }\end{array}$ & $240 \mathrm{bp}$ & Down \\
\hline \multirow[t]{2}{*}{ BE17L_vs_BE21L } & SSU72 & $\begin{array}{c}\text { F:CAAGCCACGACCAGAGAGAT } \\
\text { R:GGGTTGCCTCCTCATGGTTA }\end{array}$ & $176 \mathrm{bp}$ & Up \\
\hline & DLX5 & $\begin{array}{l}\text { F:ACCCTGCTGTGCGTAAGA } \\
\text { R:GGAAAGGAGCCTGGAAGT }\end{array}$ & $232 \mathrm{bp}$ & Down \\
\hline BE17L_vs_BE27L & PTPN6 & $\begin{array}{l}\text { F:TCTCCTATCCCGTGAGCCAA } \\
\text { R:ATTTTCTGCCCACCCCTAGC }\end{array}$ & $131 \mathrm{bp}$ & Down \\
\hline \multirow[t]{2}{*}{ BE17L_vs_BE31L } & LMAN2 & $\begin{array}{l}\text { F:GGGAGTTTTCCTTGCCCCAG } \\
\text { R:GTTGGTTCACTTTGTTCTGCCC }\end{array}$ & $196 \mathrm{bp}$ & Down \\
\hline & GALNT1 & $\begin{array}{l}\text { F:AGGGGAAGGTCGGGAAAGTT } \\
\text { R:ACAGGCAGTCCTCCTACTCAA }\end{array}$ & $201 \mathrm{bp}$ & Down \\
\hline BE17L_vs_BE34L & DCAF7 & $\begin{array}{l}\text { F:GTACAGCAGGTAGGTGTGGAA } \\
\text { R:TGCCATCCAATAAGCAGGCAT }\end{array}$ & $226 \mathrm{bp}$ & Down \\
\hline \multirow{2}{*}{ BE17L_vs_BM6L } & TACR2 & $\begin{array}{l}\text { F:CATCGCAGTGATCGTGTTGA } \\
\text { R:CGTGCAAGCTCTGTGTTGGA }\end{array}$ & $229 \mathrm{bp}$ & Up \\
\hline & TULP3 & $\begin{array}{l}\text { F:GGCCACTGGTAATGACATGCT } \\
\text { R:GTAGCTCGCTCCAAAGACAGT }\end{array}$ & $109 \mathrm{bp}$ & Down \\
\hline BE17B_vs_BE17L & $L M O 1$ & $\begin{array}{l}\text { F:GCGATTCTGTGTGGGAGACA } \\
\text { R:TTGAACCTGGGACTCGAAGC }\end{array}$ & $106 \mathrm{bp}$ & Up \\
\hline \multirow[t]{2}{*}{ BE21B_vs_BE21L } & CYGB & $\begin{array}{c}\text { F:GAGGCGGAGAAGAAGGTGATT } \\
\text { R:CGTGTCGTCCATGTGCTTGA }\end{array}$ & $147 \mathrm{bp}$ & Up \\
\hline & TMEM171 & $\begin{array}{l}\text { F:CTGATGTGAACCTCCAGGGC } \\
\text { R:TGGTGGTGGAGGTGGGAATA }\end{array}$ & $218 \mathrm{bp}$ & Down \\
\hline \multirow{2}{*}{ BE27B_vs_BE27L } & ABІ3ВР & $\begin{array}{l}\text { F:CGAAACCATCTGCTACCCCA } \\
\text { R:TGACTGACACCGGAATGGC }\end{array}$ & $213 \mathrm{bp}$ & Up \\
\hline & MTSS1 & $\begin{array}{l}\text { F:TACAGCACCCAGACGACAAC } \\
\text { R:AAACTCTTGCTGCTCTGCCT }\end{array}$ & $114 \mathrm{bp}$ & Down \\
\hline BE31B_vs_BE31L & USP7 & $\begin{array}{c}\text { F:GTCTGTCCGGGTAGAGTCGT } \\
\text { R:GAATACACACCCATGTTGCAGG }\end{array}$ & 242 bp & Down \\
\hline BE34B_vs_BE34L & FNBP4 & $\begin{array}{l}\text { F:ACGAAAATGCCGTCTCTGGT } \\
\text { R:CGAAGTTGGCGTTCCTCTCT }\end{array}$ & 172 bp & Up \\
\hline \multirow[t]{3}{*}{ BM6B_vs_BM6L } & POSTN & $\begin{array}{l}\text { F:GCAGGGAGCTGGAACTGAG } \\
\text { R:TGTTGCTCCTCCTTGTGTCC }\end{array}$ & $148 \mathrm{bp}$ & Up \\
\hline & PITX1 & $\begin{array}{l}\text { F:AGCACTCCAGTTTCGGCTAC } \\
\text { R:CTCACTTGCTCGGGTTTTGC }\end{array}$ & $226 \mathrm{bp}$ & Down \\
\hline & $\beta$-actin & $\begin{array}{l}\text { F: CCCTGTATGCCTCTGGTCG } \\
\text { R: CTCGGCTGTGGTGGTGAAG }\end{array}$ & 194 bp & \\
\hline
\end{tabular}

Note: BE17B: Breast muscle of black Muscovy duck on day 17 of the incubation period; BE17L: Leg muscle of black Muscovy duck on day 17 of the incubation period. The same below. 
Table 2. The feed composition of black Muscovy duck.

\begin{tabular}{cccc}
\hline Ingredient & Content (\%) & Nutrient & Content (\%) \\
\hline Corn & 56.00 & Crude protein & 15.700 \\
Soybean meal & 23.80 & Calcium & 0.900 \\
Corn gluten meal & 10.00 & Total phosphorus & 0.680 \\
Limestone & 7.00 & Available phosphorus & 0.450 \\
$\mathrm{CaHPO}_{4}$ & 1.50 & Salt & 0.370 \\
$\mathrm{Premix}$ & 1.00 & Lysine & 0.760 \\
$\mathrm{NaCl}$ & 0.30 & Methionine & 0.387 \\
Lys·HCl & 0.30 & Methionine + Cystine & 0.654 \\
$\mathrm{DL}-\mathrm{Met}$ & 0.10 & Isoleucine & 0.534 \\
Total & 100.00 & Threonine & 0.579 \\
& & Tryptophan & 0.194 \\
& & Crude fiber & 4.100 \\
& & Crude fat & 3.400 \\
& & Crude ash & 5.200 \\
& & Avian metabolizable energy & $2875 \mathrm{Mcal} \cdot \mathrm{kg}^{-1}$ \\
\hline
\end{tabular}

\subsection{RNA Extraction, Library Construction and Sequencing}

The total RNA was extracted from the breast and leg muscle separately using QIAzol Lysis Reagent according to the manufacturer's instructions (QIAGEN, BerlinCity Germany). The RNA integrity was measured using a 2100 Bioanalyzer (Agilent Technologies, San JoseCity USA), the RNA purity and concentration were verified by agarose gel electrophoresis and Nanodrop 2000 (Thermo, Waltham, CA, USA).

Thirty-six sequencing libraries were construct by the TruSeq PE Cluster Kit v4-cBot-HS (Illumina HiSeq X Ten platform, San Diego, CA, USA) according to the manufacturer's instructions, and the indexed samples were clustered by the Illumina's cBot cluster generation system following the manufacturer's instructions. After cluster generation, the libraries were sequenced on the Illumina platform (Illumina HiSeq X Ten platform, San Diego, CA, USA), and a paired end read of $150 \mathrm{bp}$ was generated.

\subsection{Sequencing Analysis}

After sequencing, raw reads were filtered: (1) Removing reads containing adapters or poly-N; (2) removing reads containing more than $10 \%$ of unknown nucleotides; and (3) removing low-quality reads containing more than $50 \%$ of low-quality $(\mathrm{Q}$-value $\leq 10)$ bases. Besides, quality parameters for filtered data including Q30, GC content, and sequence-duplication level were used for data filtering. All downstream analyses were based on high-quality clean data. The filtered reads were mapped to the Anas platyrhynchos (Ap) genome sequence (https://www.ncbi.nlm.nih.gov/genome/?term=DUCK) and annotated transcripts (https://www.ncbi.nlm.nih.gov/assembly/GCF_003850225.1). Based on the Ap genome, further analyses and annotation have been carried out for a perfect matched reads or one mismatched reads. Then, the HISAT 2 tool software were used to map with the Ap genome.

\subsection{Analysis of SNP/InDel}

According to the results of the HISAT 2 comparison between the reads and the Ap genome sequence of each sample, the GATK software was used to find the single base mismatch between the sequenced sample and the Ap genome, and identify the potential single nucleotide polymorphism (SNP) site. The insertion-deletion (InDel) of the sample was also detected by the GATK software. According to the position of heterotopia in the Ap genome, the region where the mutation occurred (intergenic region, gene region or CDS region, etc.) and the effect of mutation (synonymous or non-synonymous mutation, etc.) were got by the SNPEFF software. 


\subsection{Prediction of Variable Splices}

The results of HISAT 2 comparison were spliced by the StringTie software. The variable splicing types and corresponding expressions of each sample were obtained by the ASprofile software. The differentially expressed isoforms were estimated by the Cufflink.

\subsection{Analysis of DEGs}

To analyze DEGs, gene coverage and gene expression level were calculated. Gene coverage is the percentage of a gene covered by reads. The unigene expression was calculated and normalized to FPKM (fragments per kilobase per transcript per million mapped reads) based on FPKM $(A)=c D N A$ Fragments/[Mapped Fragments (Millions) Transcript Length (kb)], where cDNA Fragments referred to the number of fragments compared to a transcript; Mapped Fragments (Millions) referred to the total number of fragments compared to a transcript, in $1 \times 10^{6}$ units; Script Length $(\mathrm{kb})$ referred to the length of the transcript, in $1 \times 10^{3}$ bases units.

Differential expression was analyzed using the DESeq 2, and the false discovery rate (FDR) was calculated to calibrate the significant level and eliminate the influence of random fluctuations and errors. The unigenes with Fold change $\geq 2$ and FDR $<0.01$ were considered DEGs. The Benjamin-Hochberg correction method was used to correct the significant $p$-value of the original hypothesis test, and FDR was used as the key indicator for screening DEGs.

\subsection{Analysis of GO and KEGG Pathway}

GO enrichment analysis was performed using the Goseq R software package, and the enrichment of DEGs in KEGG was tested using the KOBAS software. Besides, gene functions were annotated with the following databases, including $\mathrm{Nr}$ (NCBI non-redundant protein sequences, ftp://ftp.ncbi. nih.gov/blast/db/); Nt (NCBI non-redundant nucleotide sequences, ftp://ftp.ncbi.nih.gov/blast/db/); Pfam (Protein family, http://pfam.xfam.org/); KOG/COG (Clusters of Orthologous Groups of proteins, http://www.ncbi.nlm.nih.gov/KOG/; http://www.ncbi.nlm.nih.gov/COG/); Swiss-Prot (a manually annotated and reviewed protein sequence database, http://www.uniprot.org/); GO (Gene Ontology, http://www.geneontology.org/); KO (KEGG Ortholog database, https://www.genome.jp/kegg/ko.html).

\subsection{RNA-seq Validation by $q P C R$}

In order to confirm the reliability of RNA-seq results, 26 representative responsive genes of breast and leg muscle in black Muscovy duck were selected for qPCR, respectively. Duck $\beta$-actin (accession number: NC_040060.1) was measured as the housekeeping gene. RNA with an A260/280 ratio between 1.9 and 2.1, and A260/230 ratio > 2.0 were used for cDNA synthesis. The list of primers were described in Table 1. Each reaction mixture contained $5 \mu \mathrm{L}$ of TransStart Tip Green qPCR SuperMix (Transgen, Beijing, China), $0.8 \mu \mathrm{L}$ of cDNA (400 ng/ $\mu \mathrm{L}), 0.3 \mu \mathrm{L}$ of each primer $(10 \mu \mathrm{M})$ and $3.6 \mu \mathrm{L}$ ddH2O in $10 \mu \mathrm{L}$ final volume using EcoRT48 (OSA, London, UK). The optimal reaction procedure included $95^{\circ} \mathrm{C}$ for $30 \mathrm{~s}$, followed by 40 cycles of $95^{\circ} \mathrm{C}$ for $5 \mathrm{~s}, 60^{\circ} \mathrm{C}$ for $30 \mathrm{~s}$, then $95^{\circ} \mathrm{C}$ for $15 \mathrm{~s}, 55^{\circ} \mathrm{C}$ for $15 \mathrm{~s}, 95^{\circ} \mathrm{C}$ for $15 \mathrm{~s}$. To derive the relative expression value, $2^{-\Delta \Delta \mathrm{Ct}}$ method was adopted. The results were expressed as mean \pm SD of at least three independent biological replicates. Statistical analyses of the data were conducted in SPSS 20.0. Significant differences in duck muscle gene expression in different growth periods were determined by one-way ANOVA followed by Tukey's test and Duncan's test.

\section{Results}

\subsection{Transcriptome Profiles}

In this study, a total of 36 libraries were established from the breast and leg muscles of duck in BE17, BE21, BE27, BE31, BE34, and BM6. The gene expression of black Muscovy duck skeletal 
muscle transcriptome at different growth stages was systematically analyzed by high-throughput RNA sequencing. All samples had an RNA integrity number (RIN) $>7.5$, and a RNA concentration $\geq 125.2 \mathrm{ng} / \mu \mathrm{L}$ (Table S1). After quality control, clean reads of samples ranging from 19,700,766 to $33,105,790$ (24,559,860 on average), GC contents of the samples were between $49.19 \%$ and $56.80 \%$, and $\geq$ Q30 (\%) were $91.36 \%$ to $93.80 \%$ (Table 3). In total reads of the samples, over $26,201,608$ high-quality reads per sample were mapped to the Ap genome and used for gene expression analysis, where "Uniq Mapped Reads" ranging from 23,077,005 (51.13\%) to 30,289,226 (69.98\%) and "Multiple Map Reads" ranging from 1,297,423 (2.92\%) to 11,929,431 (23.55\%). Besides, the number of Reads aligned to the positive strand in the Ap genome were 9,228,720 to 20,801,712 and the number of reads aligned to the negative strand in the Ap genome were between 13,086,584 and 21,955,456 (Table S2).

Table 3. RNA-Seq data from breast muscle and leg muscle of black Muscovy duck.

\begin{tabular}{ccccc}
\hline Samples & Clean Reads & Clean Bases & GC Content & $\geq \mathbf{Q 3 0} \mathbf{( \% )}$ \\
\hline BE17B1 & $26,764,472$ & $7,980,103,934$ & $50.51 \%$ & $93.57 \%$ \\
BE17B2 & $32,024,936$ & $9,563,668,162$ & $50.63 \%$ & $93.35 \%$ \\
BE17B3 & $23,594,320$ & $7,046,658,352$ & $50.99 \%$ & $92.86 \%$ \\
BE17L1 & $26,550,573$ & $7,917,527,738$ & $50.81 \%$ & $93.07 \%$ \\
BE17L2 & $33,105,790$ & $9,881,964,696$ & $51.01 \%$ & $92.80 \%$ \\
BE17L3 & $22,233,811$ & $6,608,083,230$ & $50.44 \%$ & $93.75 \%$ \\
BE21B1 & $21,356,816$ & $6,372,442,332$ & $50.93 \%$ & $93.10 \%$ \\
BE21B2 & $23,023,064$ & $6,874,209,792$ & $50.50 \%$ & $92.30 \%$ \\
BE21B3 & $22,232,157$ & $6,643,515,660$ & $50.10 \%$ & $91.93 \%$ \\
BE21L1 & $27,233,943$ & $8,132,501,326$ & $50.35 \%$ & $92.25 \%$ \\
BE21L2 & $23,821,161$ & $7,114,195,066$ & $50.77 \%$ & $92.71 \%$ \\
BE21L3 & $25,252,424$ & $7,545,013,174$ & $51.35 \%$ & $92.99 \%$ \\
BE27B1 & $26,005,019$ & $7,766,530,628$ & $51.05 \%$ & $92.74 \%$ \\
BE27B2 & $26,902,913$ & $8,034,045,734$ & $50.82 \%$ & $92.73 \%$ \\
BE27B3 & $24,226,391$ & $7,227,540,800$ & $51.53 \%$ & $92.75 \%$ \\
BE27L1 & $23,634,707$ & $7,060,587,498$ & $51.47 \%$ & $92.59 \%$ \\
BE27L2 & $25,561,499$ & $7,630,071,354$ & $51.34 \%$ & $93.31 \%$ \\
BE27L3 & $29,341,501$ & $8,760,492,104$ & $51.16 \%$ & $93.13 \%$ \\
BE31B1 & $21,708,384$ & $6,481,320,616$ & $50.43 \%$ & $93.32 \%$ \\
BE31B2 & $21,045,091$ & $6,284,463,090$ & $50.48 \%$ & $92.65 \%$ \\
BE31B3 & $23,666,137$ & $7,071,687,724$ & $50.01 \%$ & $93.80 \%$ \\
BE31L1 & $21,773,785$ & $6,504,542,434$ & $50.79 \%$ & $92.41 \%$ \\
BE31L2 & $19,700,766$ & $5,883,221,398$ & $50.94 \%$ & $92.35 \%$ \\
BE31L3 & $25,067,398$ & $7,480,770,550$ & $50.95 \%$ & $92.68 \%$ \\
BE34B1 & $19,970,569$ & $5,959,632,696$ & $51.20 \%$ & $91.89 \%$ \\
BE34B2 & $21,641,494$ & $6,468,354,774$ & $50.57 \%$ & $92.51 \%$ \\
BE34B3 & $24,247,593$ & $7,240,167,310$ & $50.04 \%$ & $91.36 \%$ \\
BE34L1 & $19,825,346$ & $5,925,722,250$ & $49.19 \%$ & $92.01 \%$ \\
BE34L2 & $20,622,571$ & $6,154,061,186$ & $50.82 \%$ & $91.72 \%$ \\
BE34L3 & $21,504,291$ & $6,418,738,234$ & $50.92 \%$ & $91.70 \%$ \\
BM6B1 & $27,888,927$ & $8,312,322,988$ & $52.05 \%$ & $93.09 \%$ \\
BM6B2 & $26,315,704$ & $7,841,240,550$ & $51.31 \%$ & $93.29 \%$ \\
BM6B3 & $32,141,926$ & $9,592,590,862$ & $52.51 \%$ & $92.91 \%$ \\
BM6L1 & $22,567,829$ & $6,744,703,784$ & $56.80 \%$ & $92.26 \%$ \\
BM6L2 & $25,330,860$ & $7,561,056,178$ & $53.01 \%$ & $92.95 \%$ \\
BM6L3 & $26,270,786$ & $7,826,518,320$ & $50.75 \%$ & $93.01 \%$ \\
\hline
\end{tabular}

\subsection{Annotation and Classification of SNP/InDel}

The number of SNP loci, the proportion of transition type and transversion type, as well as the ratio of heterozygous SNP loci from each sample were counted, the results were shown in Table 4 . There were 23,381 to 634,028 SNPs in skeletal muscle of black Muscovy duck at different growth stages, where the 
total numbers of SNPs in the genic region were 20,572 to 574,484, the numbers of SNPs between genes were 2809 to 59,544 . Besides, the percentage that the transition-type SNP accounts for all SNP locis were over $71.12 \%$, the percentage that the transversion-type SNP loci accounts for all SNP sites were between $23.66 \%$ and $28.88 \%$, and the percentage that the heterozygous SNPs account for all SNPs were $4.27 \%$ to $48.09 \%$. The annotation results of SNP and InDel were shown in Figure 1. The annotations of SNP were mainly distributed in "INTRON", "SYNONYMOUS_CODING", and "UTR_3_PRIME". The annotations of InDel were mainly distributed in "INTRON", "UTR_3_PRIME", and "DOWNSTREAM".

Table 4. Single nucleotide polymorphism (SNP) statistics of each sample.

\begin{tabular}{|c|c|c|c|c|c|c|}
\hline Samples & SNP Number & Genic SNP & Intergenic SNP & Transition & Transversion & Heterozygosity \\
\hline BE17B2 & 533,462 & 479,697 & 53,765 & $71.91 \%$ & $28.09 \%$ & $5.18 \%$ \\
\hline BE17L1 & 444,914 & 405,784 & 39,130 & $72.19 \%$ & $27.81 \%$ & $5.32 \%$ \\
\hline BE17L2 & 530,400 & 482,360 & 48,040 & $71.78 \%$ & $28.22 \%$ & $5.49 \%$ \\
\hline BE21B2 & 468,195 & 420,675 & 47,520 & $71.82 \%$ & $28.18 \%$ & $4.96 \%$ \\
\hline BE21B3 & 440,935 & 395,737 & 45,198 & $71.80 \%$ & $28.20 \%$ & $4.73 \%$ \\
\hline BE21L1 & 437,821 & 400,429 & 37,392 & $72.14 \%$ & $27.86 \%$ & $5.25 \%$ \\
\hline BE21L2 & 389,009 & 356,065 & 32,944 & $72.51 \%$ & $27.49 \%$ & $5.24 \%$ \\
\hline BE21L3 & 347,547 & 315,990 & 31,557 & $72.68 \%$ & $27.32 \%$ & $5.79 \%$ \\
\hline BE27L1 & 406,931 & 374,739 & 32,192 & $72.26 \%$ & $27.74 \%$ & $4.27 \%$ \\
\hline BE27L2 & 412,229 & 379,360 & 32,869 & $72.25 \%$ & $27.75 \%$ & $5.59 \%$ \\
\hline BE27L3 & 446,540 & 410,485 & 36,055 & $71.98 \%$ & $28.02 \%$ & $5.50 \%$ \\
\hline BE31B1 & 463,381 & 425,359 & 38,022 & $71.92 \%$ & $28.08 \%$ & $5.23 \%$ \\
\hline BE31B2 & 475,408 & 426,377 & 49,031 & $71.77 \%$ & $28.23 \%$ & $5.28 \%$ \\
\hline BE31B3 & 437,040 & 398,822 & 38,218 & $71.91 \%$ & $28.09 \%$ & $5.40 \%$ \\
\hline BE31L1 & 293,728 & 264,407 & 29,321 & $72.66 \%$ & $27.34 \%$ & $5.07 \%$ \\
\hline BE31L2 & 290,393 & 261,387 & 29,006 & $72.68 \%$ & $27.32 \%$ & $4.31 \%$ \\
\hline BE31L3 & 356,589 & 317,875 & 38,714 & $72.17 \%$ & $27.83 \%$ & $5.23 \%$ \\
\hline BE34B1 & 353,066 & 320,045 & 33,021 & $72.24 \%$ & $27.76 \%$ & $5.03 \%$ \\
\hline BM6B3 & 114,505 & 104,733 & 9772 & $73.88 \%$ & $26.12 \%$ & $38.46 \%$ \\
\hline BM6L1 & 23,381 & 20,572 & 2809 & $76.34 \%$ & $23.66 \%$ & $48.09 \%$ \\
\hline BM6L2 & 66,117 & 60,659 & 5458 & $75.23 \%$ & $24.77 \%$ & $44.45 \%$ \\
\hline BM6L3 & 85,270 & 77,902 & 7368 & $74.24 \%$ & $25.76 \%$ & $40.48 \%$ \\
\hline
\end{tabular}

SNP Number: Total numbers of SNPs; Genic SNP: Total numbers of SNPs in the genic region; Intergenic SNP: Total numbers of SNPs between genes; Transition: The percentage that the transition-type SNP accounts for all SNP locis; Transversion: The percentage that the transversion-type SNP loci accounts for all SNP sites; Heterozygosity: The percentage that the heterozygous SNPs account for all SNPs.

\subsection{Prediction of Alternative Splice (AS)}

The chromosomal position of each transcript was obtained by aligning the sequence to the Ap genome. Twelve different splice patterns in the transcriptome data of duck skeletal muscle were detected: (A) TSS: Alternative 5' first exon (transcription start site) the first exon splicing; (B) TTS: Alternative 3' last exon (transcription terminal site) the last exon splicing; (C) SKIP: Skipped exon single exon skipping; (D) XSKIP: Approximate SKIP single exon skipping (fuzzy boundary); (E) MSKIP: Multi-exon SKIP multi-exon skipping; (F) XMSKIP: Approximate MSKIP multi-exon skipping (fuzzy boundary); 
(G) IR: Intron retention single intron retention; (H) XIR: Approximate IR single intron retention (fuzzy boundary); (I) MIR: Multi-IR multi-intron retention; (J) XMIR: Approximate MIR multi-intron retention (fuzzy boundary); (K) AE: Alternative exon ends (5', 3', or both); (L) XAE: Approximate $\mathrm{AE}$ variable $5^{\prime}$ or $3^{\prime}$ end (fuzzy boundary). As shown in Figure 2, the average number of AS events per sample was 37,267 , and the predicted number of variable splices in each sample were mainly concentrated in TSS and TTS.

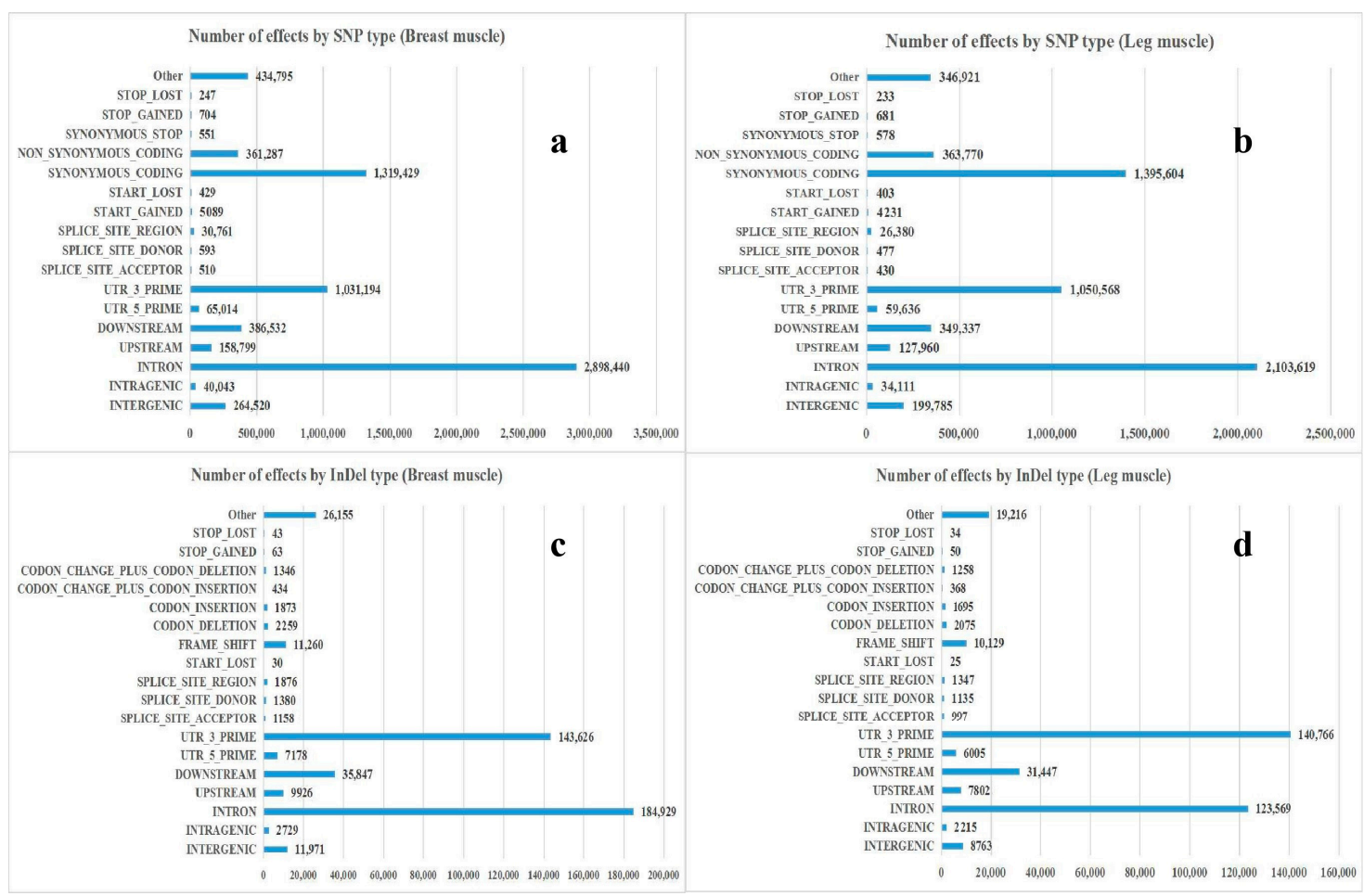

Figure 1. Annotation and classification of SNP/InDel. (a) The annotation result of SNP in breast muscle; (b) the annotation result of SNP in leg muscle; (c) the annotation result of InDel in breast muscle;

(d) the annotation result of InDel in leg muscle.

\subsection{Analysis of DEGs}

The relative expression of gene was normalized as fragments per kilobase of exon model per million mapped reads (FPKM), which was proportional to the number of CDNA fragments originated by gene transcription. Statistical analysis of DEGs in breast and leg muscle of black Muscovy ducks at different stages were shown in Table 5. In breast muscle, differential gene expression analysis of BE17B_vs_BE21B showed that 410 genes were significantly differentially expressed (Fold change $\geq 2$ and FDR $<0.01$ at $p<0.05$, the same below), including 218 up-regulated and 192 down-regulated genes. Moreover, there were 1958 significantly expressed genes from BE17B_vs_BE27B, among which 1162 were up-regulated genes and 796 were down-regulated genes. A number of 1517 DEGs were detected from BE17B_vs_BE31B, the number of up-regulated genes were 925 and the down-regulated genes was 592 respectively. There were 1460 DEGs from BE17B_vs_BE34B, including 852 up-regulated genes and 608 down-regulated genes. Besides, 5377 DEGs were found in BE17B_vs_BM6B, of which 2580 were up-regulated genes and 2797 were down regulated genes (Figure S1).

In leg muscle, the results showed that there were 655 DEGs, including 371 up-regulated genes and 284 down-regulated genes from BE17L_vs_BE21L. Moreover, 2866 DEGs were discovered in BE17L_vs_BE27L, among which 1606 genes were up-regulated and 1260 genes were down-regulated. From BE17L_vs_BE31L, there were 4413 significantly expressed genes, among which 2440 were up-regulated genes and 1973 were down-regulated genes. 4326 DEGs were detected from BE17B_vs_BE34B, out of which 2374 up-regulated and 1952 down-regulated genes were identified 
as significantly differentially expressed. Besides, 4560 DEGs were discovered in BE17L_vs_BM6L, and 2303 DEGs were up-regulated genes and 2257 DEGs were down-regulated genes (Figure S2).

In the comparison of breast and leg muscle, there were 214, 1256, 195, 1226, 19, and 104 significantly expressed genes from BE17B_vs_BE17L, BE21B_vs_BE21L, BE27B_vs_BE27L, BE31B_vs_BE31L, BE34B_vs_BE34L, and BM6B_vs_BM6L, among which 162, 523, 51, 606, 5, and 58 were up-regulated genes and 52, 733, 144, 620, 14, and 46 were down-regulated genes (Figure S3). The top 5 up- and down-regulated genes between the comparison samples were listed in Table S3. Hierarchical clustering of DEGs showed that the samples clustered based on condition (Figures S4-S6).
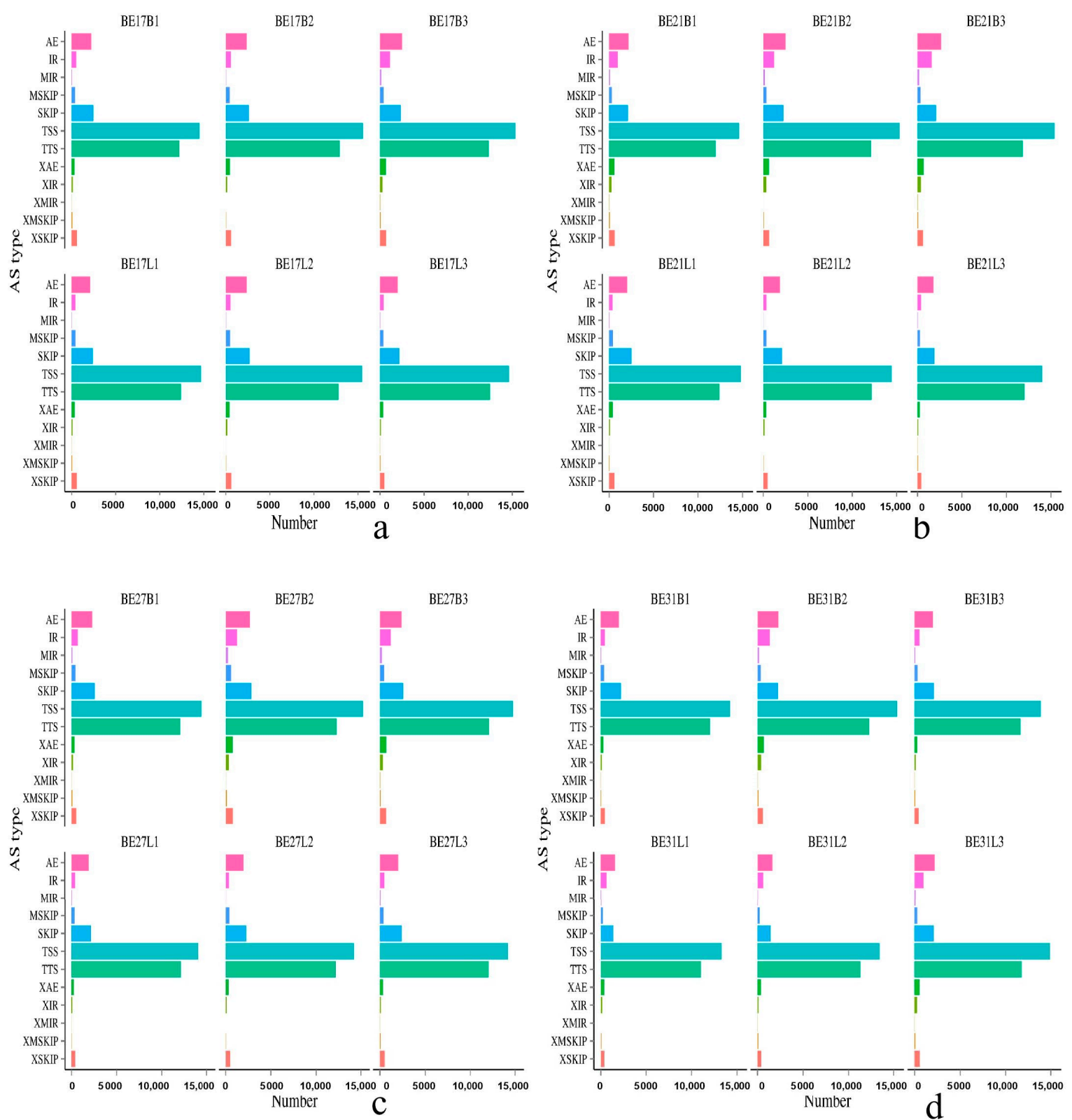

Figure 2. The predicted number of variable splices in black Muscovy ducks during different incubation stages. (a-f) represent the predicted number of variable splices in black Muscovy ducks on day 17, $21,27,31$, and 34 of incubation and postnatal 6-month-old, respectively. Note: The horizontal axis represents number to one of alternative transcripts, the vertical axis represents types of alternative splicing events. 
Table 5. Statistical results of differentially expressed genes.

\begin{tabular}{cccc}
\hline DEGs & $\begin{array}{c}\text { DEGnumber } \\
\text { (newGene) }\end{array}$ & $\begin{array}{c}\text { Up-Regulated } \\
\text { (newGene) }\end{array}$ & $\begin{array}{c}\text { Down-Regulated } \\
\text { (newGene) }\end{array}$ \\
\hline BE17B_vs_BE21B & $410(24)$ & $218(22)$ & $192(2)$ \\
BE17B_vs_BE27B & $1958(148)$ & $1162(138)$ & $796(10)$ \\
BE17B_vs_BE31B & $1517(108)$ & $925(101)$ & $592(7)$ \\
BE17B_vs_BE34B & $1460(79)$ & $852(73)$ & $608(6)$ \\
BE17B_vs_BM6B & $5377(339)$ & $2580(187)$ & $2797(152)$ \\
BE17L_vs_BE21L & $655(24)$ & $371(16)$ & $284(8)$ \\
BE17L_vs_BE27L & $2866(185)$ & $1606(148)$ & $1260(37)$ \\
BE17L_vs_BE31L & $4413(344)$ & $2440(295)$ & $1973(49)$ \\
BE17L_vs_BE34L & $4326(342)$ & $2374(299)$ & $1952(43)$ \\
BE17L_vs_BM6L & $4560(303)$ & $2303(168)$ & $2257(135)$ \\
BE17B_vs_BE17L & $214(13)$ & $162(6)$ & $52(7)$ \\
BE21B_vs_BE21L & $1256(194)$ & $523(20)$ & $733(174)$ \\
BE27B_vs_BE27L & $195(27)$ & $51(2)$ & $144(25)$ \\
BE31B_vs_BE31L & $1226(96)$ & $606(63)$ & $620(33)$ \\
BE34B_vs_BE34L & $19(3)$ & $5(1)$ & $14(2)$ \\
BM6B_vs_BM6L & $104(13)$ & $58(6)$ & $46(7)$ \\
\hline
\end{tabular}

\subsection{Analysis of GO Annotation and KEGG Pathway}

Functional annotations of DEGs in the database were performed, and the number of annotated genes were shown in Table S4. The total number of DEGs annotated were between 17 and 5253, where the COG were 3 to 1775, the GO were 14 to 4191 and the KEGG were 5 to 3542. Besides, the number of KOG ranged from 10 to 3788, the NR ranged from 17 to 5231, the Pfam ranged from 14 to 4816. Moreover, the Swiss-Prot were between 12 and 3788, the eggNOG were between 15 and 5118 .

To gain valuable insight into the molecular functions of the genes potentially associated with muscle development, the identified DEGs were categorize into three functional groups depending on gene ontology: Biological Process, Molecular Function and Cellular Component. In breast muscle, GO analysis was performed on the common DEGs in BE17B_vs_BE21B indicated that biological processes, including regulation of calcium ion import, regulation of muscle filament sliding speed, dorsal root ganglion development, and negative regulation of fibroblast growth factor receptor signaling pathway were significantly enriched. The common DEGs in BE17B_vs_BE27B were primarily enriched in biological processes of actin binding, positive regulation of myoblast proliferation, cell division, positive regulation of cell proliferation and regulation of actin cytoskeleton organization. Besides, most genes that were involved in the biological processes of regulation of muscle filament sliding, skeletal muscle fiber development, positive regulation of myoblast differentiation and muscle cell cellular homeostasis were mainly enriched in BE31B compared to that of BE17B. The terms of regulation of cell cycle, positive regulation of fibroblast proliferation and positive regulation of substrate-dependent cell migration, cell attachment to substrate were enriched in BE34B compared to BE17B. Additionally, several fundamental biological processes were found to be notably enriched in BE17B_vs_BM6B, such as translation, immune response, regulation of cell size and regulation of cell growth (Figures 3-5). 

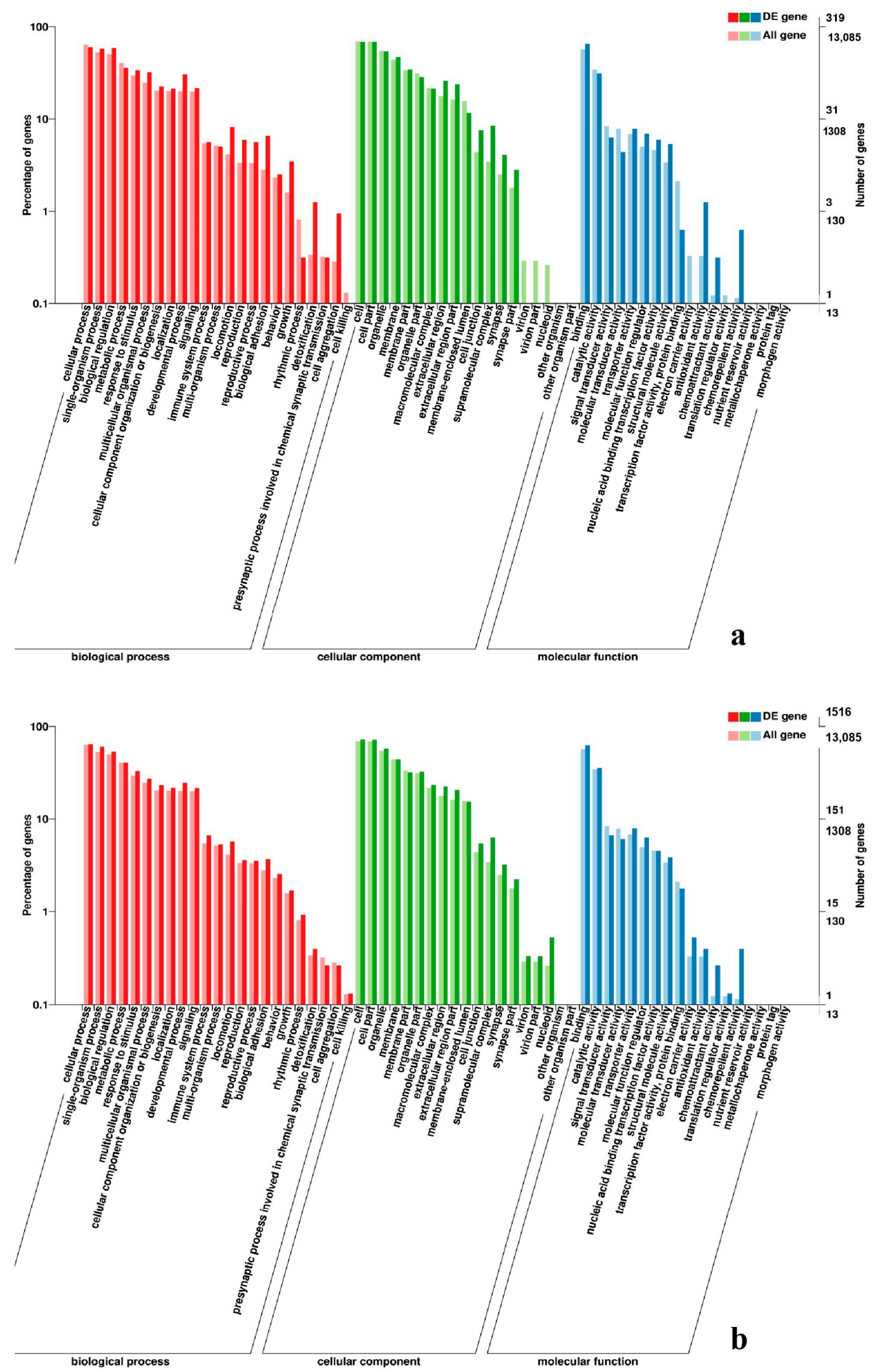

Figure 3. GO enrichment analysis of differentially expressed genes (DEGs) in breast muscle. (a) BE17B_vs_BE21B; (b) BE17B_vs_BE27B. Note: The abscissa were GO terms, the ordinate on the left was percentage of genes in all genes annotated with $G O$, right was the number of gene. The same below. 

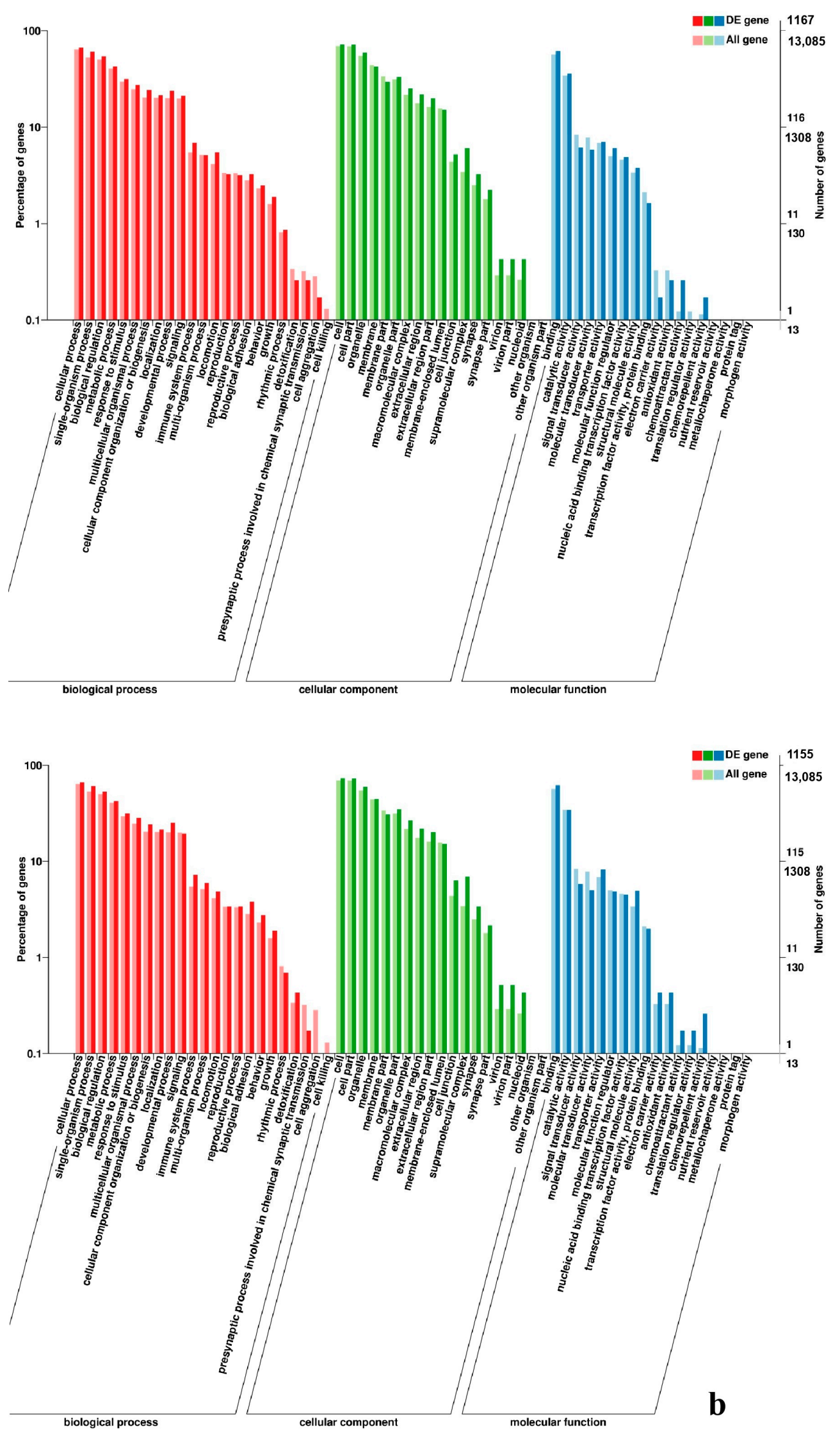

Figure 4. GO enrichment analysis of DEGs in breast muscle (a) BE17B_vs_BE31B; (b) BE17B_vs_BE34B. 


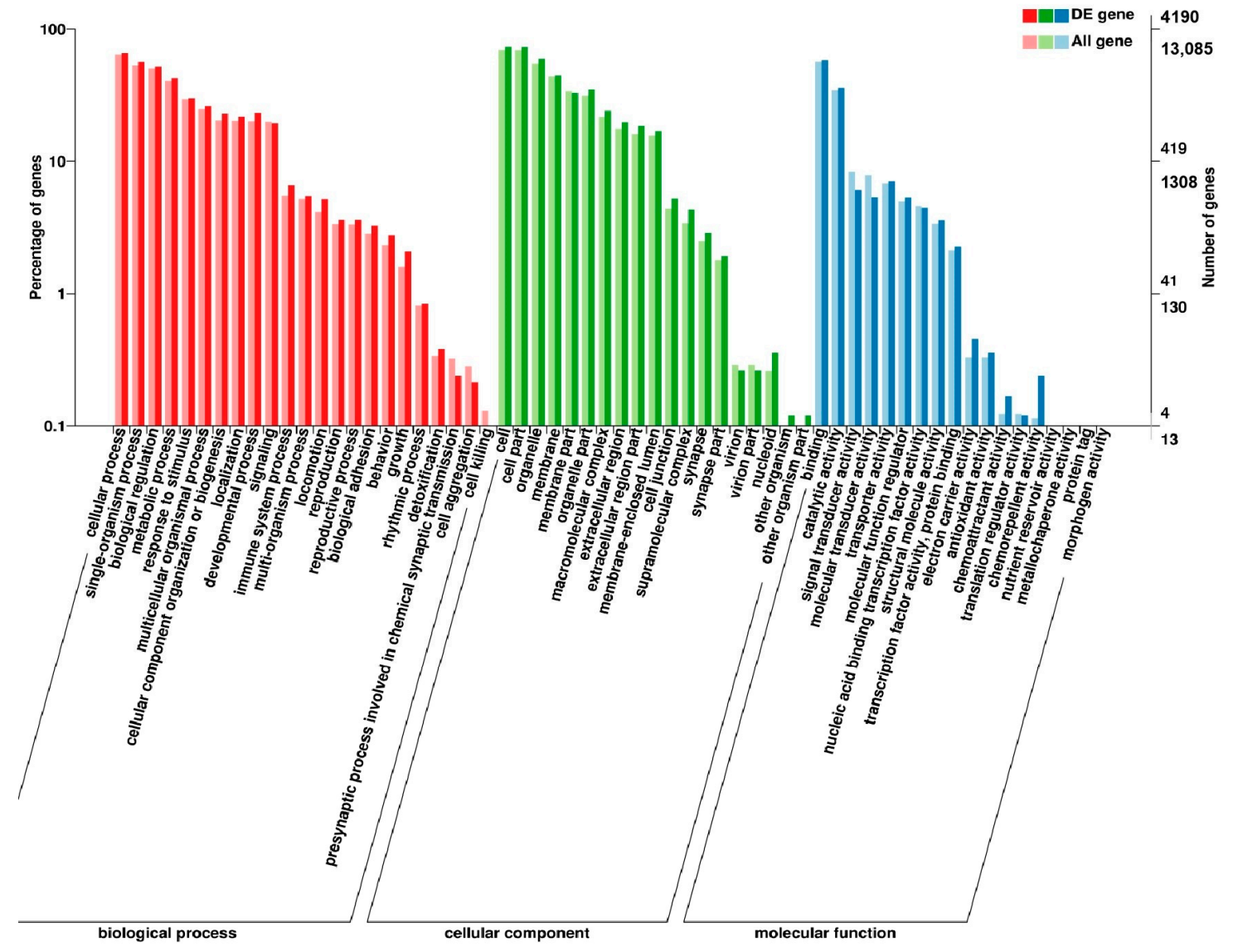

Figure 5. GO enrichment analysis of DEGs in breast muscle of BE17B_vs_BM6B.

In leg muscle, DEGs were mainly enriched in biological processes of cell proliferation, skeletal muscle fiber development, skeletal muscle tissue development, regulation of muscle filament sliding, positive regulation of cell division in BE17L_vs_BE21L, and regulation of transcription involved in cell fate commitment, calcium-mediated signaling, glucose transport in BE17L_vs_B27L, respectively. Compared to BE17L, most genes that were involved in the biological processes of cell maturation, embryonic limb morphogenesis, chordate embryonic development and immune response were mainly enriched in BE31L. DEGs in BE17L_vs_BE34L and BE17L_vs_BM6L were primarily enriched in biological processes of embryonic hindlimb morphogenesis, positive regulation of protein process, regulation of actin cytoskeleton organization, positive regulation of cell proliferation and Wnt receptor catabolic process, embryonic hindlimb morphogenesis, glucose transport, protein folding, and immune response, respectively (Figures 6-8). In the comparison of breast and leg muscle, there were some terms mainly reached in biological processes of myoblast migration involved in skeletal muscle regeneration, positive regulation of glucocorticoid receptor signaling pathways, regulation of multicellular organism growth in BE17B_vs_BE17L, and positive regulation of cellular process, metabolic process, fibroblast migration in BE21B_vs_BE21L, respectively. In BE27B_vs_BE27L and BE31B_vs_B31L, DEGs were primarily enriched in biological processes, including positive regulation of MHC class I biosynthetic process, immune response, metabotic process and regulation of cell shape, embryonic organ development, translation, and muscle structure morphogenesis, respectively. DEGs in BE34B_vs_BE34L were primarily enriched in biological processes of skeletal muscle cell differentiation, skeletal muscle fiber adaptation, myotube differentiation involved in skeletal muscle regeneration, positive regulation of skeletal muscle tissue regeneration. Additionally, several biological processes were found to be notably enriched in BM6B_vs_BM6L, such as muscle structure development, embryonic skeletal joint morphogenesis, myoblast fate commitment, and negative regulation of skeletal muscle tissue development (Figures 9-11, Table 6). 

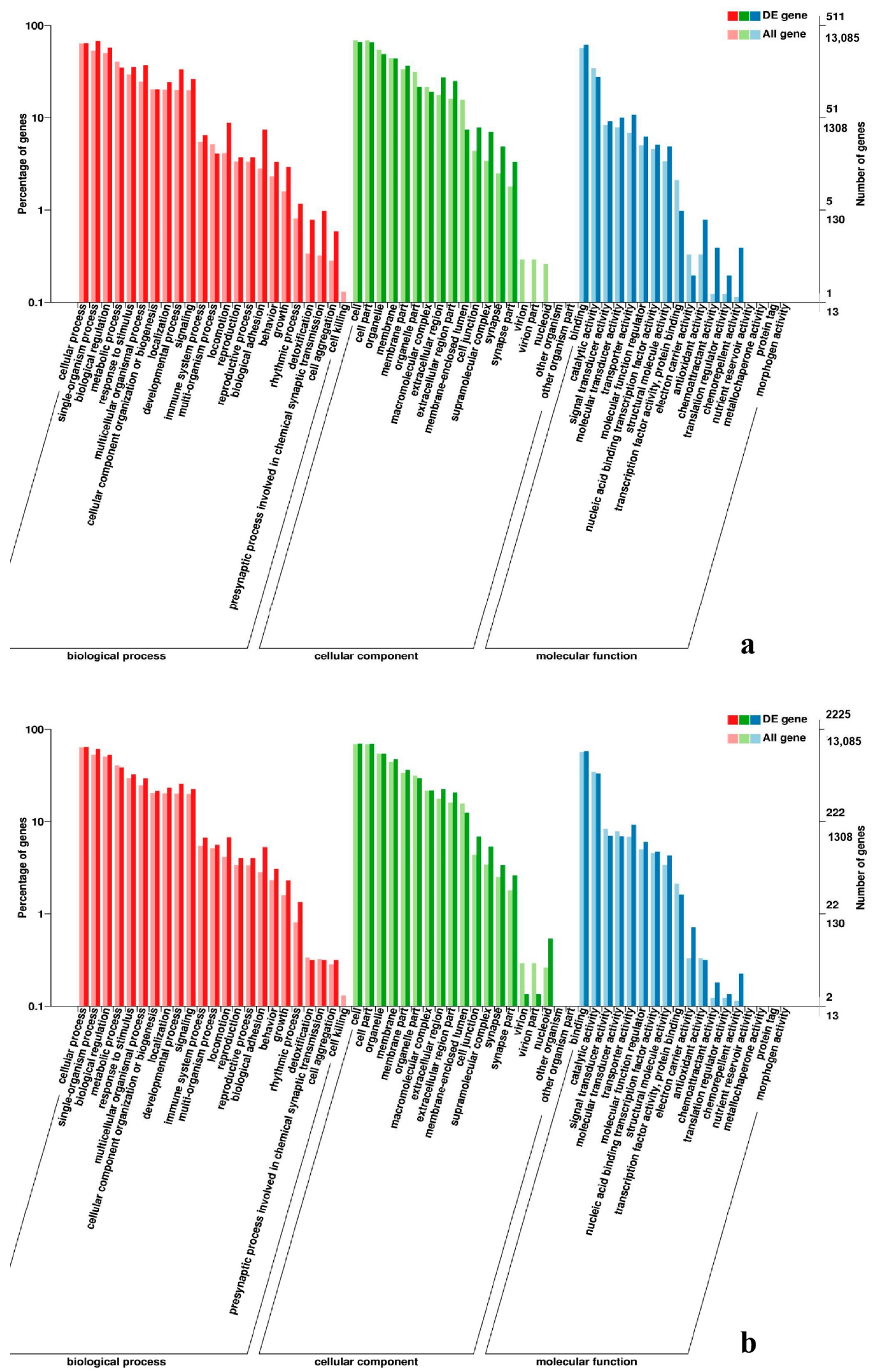

Figure 6. GO enrichment analysis of DEGs in leg muscle. (a) BE17L_vs_BE21L; (b) BE17L_vs_BE27L. 

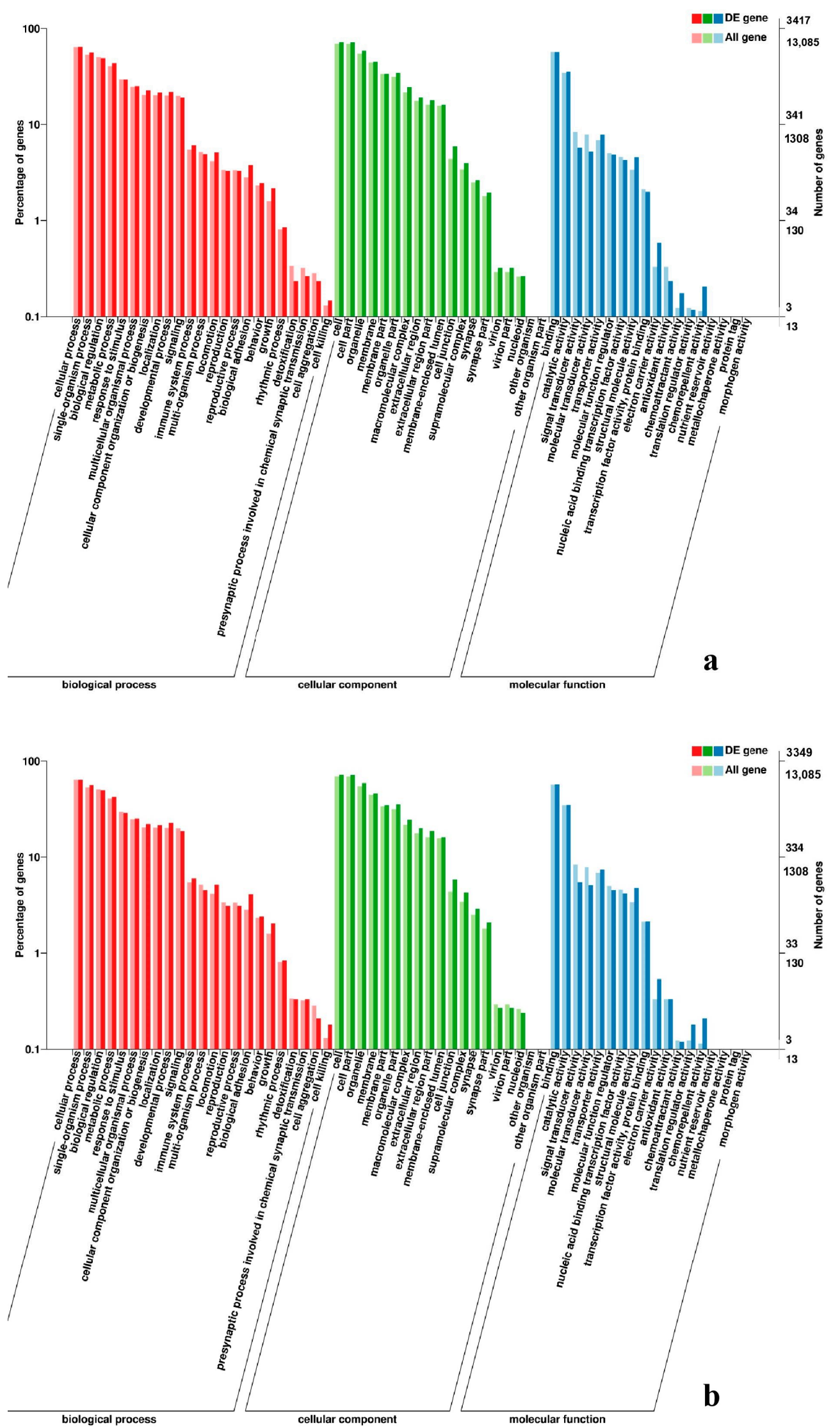

Figure 7. GO enrichment analysis of DEGs in leg muscle. (a) BE17L_vs_BE31L; (b) BE17L_vs_BE34L. 


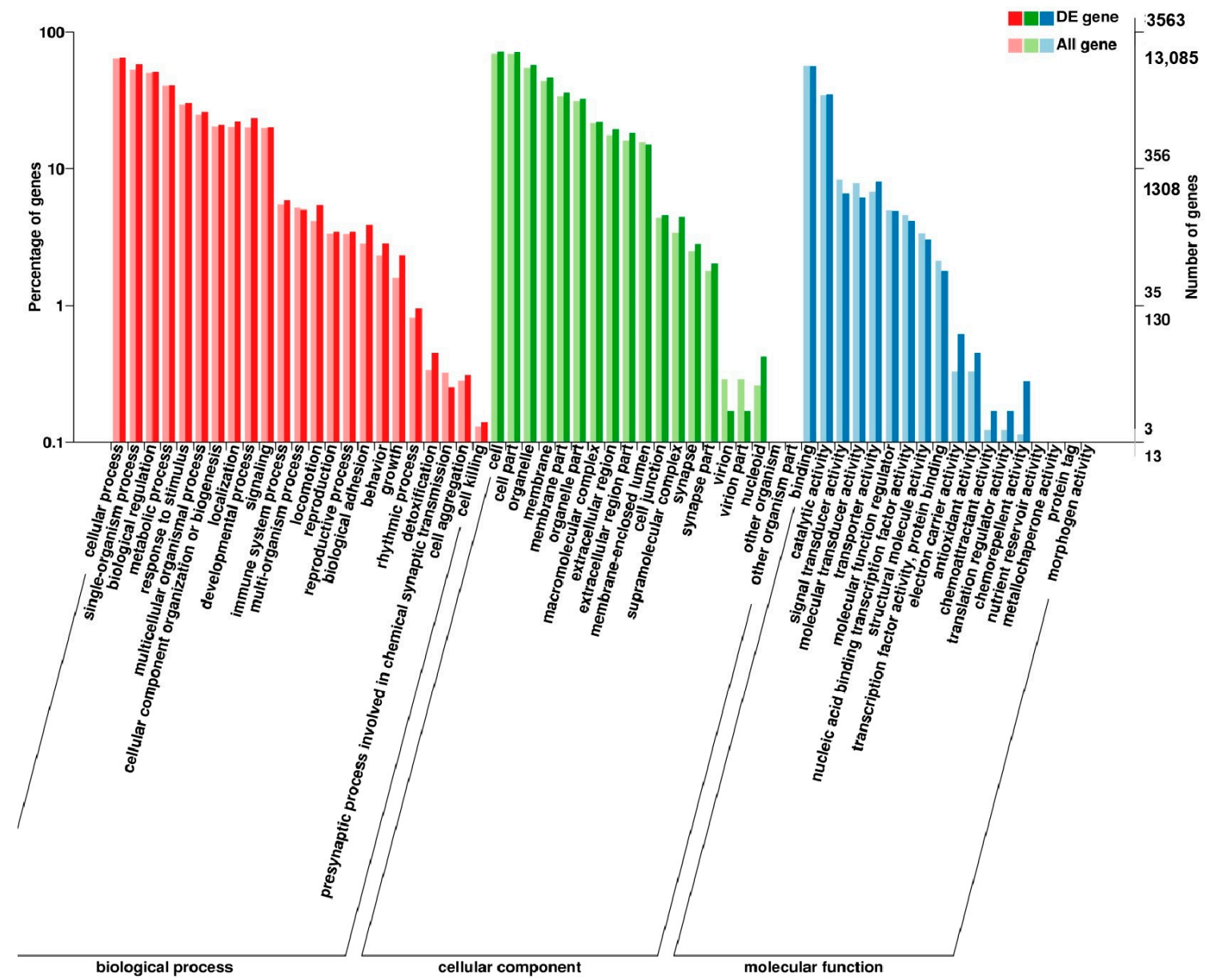

Figure 8. GO enrichment analysis of DEGs in leg muscle of BE17L_vs_BM6L.

Besides, Cluster of Orthologous Groups (COG) database was constructed using phylogeny of bacteria, algae, and eukaryotic. The products of genes could be orthologously classified using the COG database (Figures S7-S9). KEGG analysis of DEGs revealed that Focal adhesion, Regulation of actin cytoskeleton, MAPK signaling pathway, Wnt signaling pathway, ECM-receptor interaction, neuroactive ligand-receptor interaction, purine metabolism, calcium signaling pathway, endocytosis, ErbB signaling pathway, glucagon signaling pathway, RIG-I-like receptor signaling pathway, Insulin signaling pathway, cell cycle, apoptosis, oxidative phosphorylation phosphatidylinositol signaling system, cell adhesion molecules (CAMs), biosynthesis of amino acids and Ribosome were the most enriched for the DEGs at different developmental stages (Figures 12-20, Table 7). 

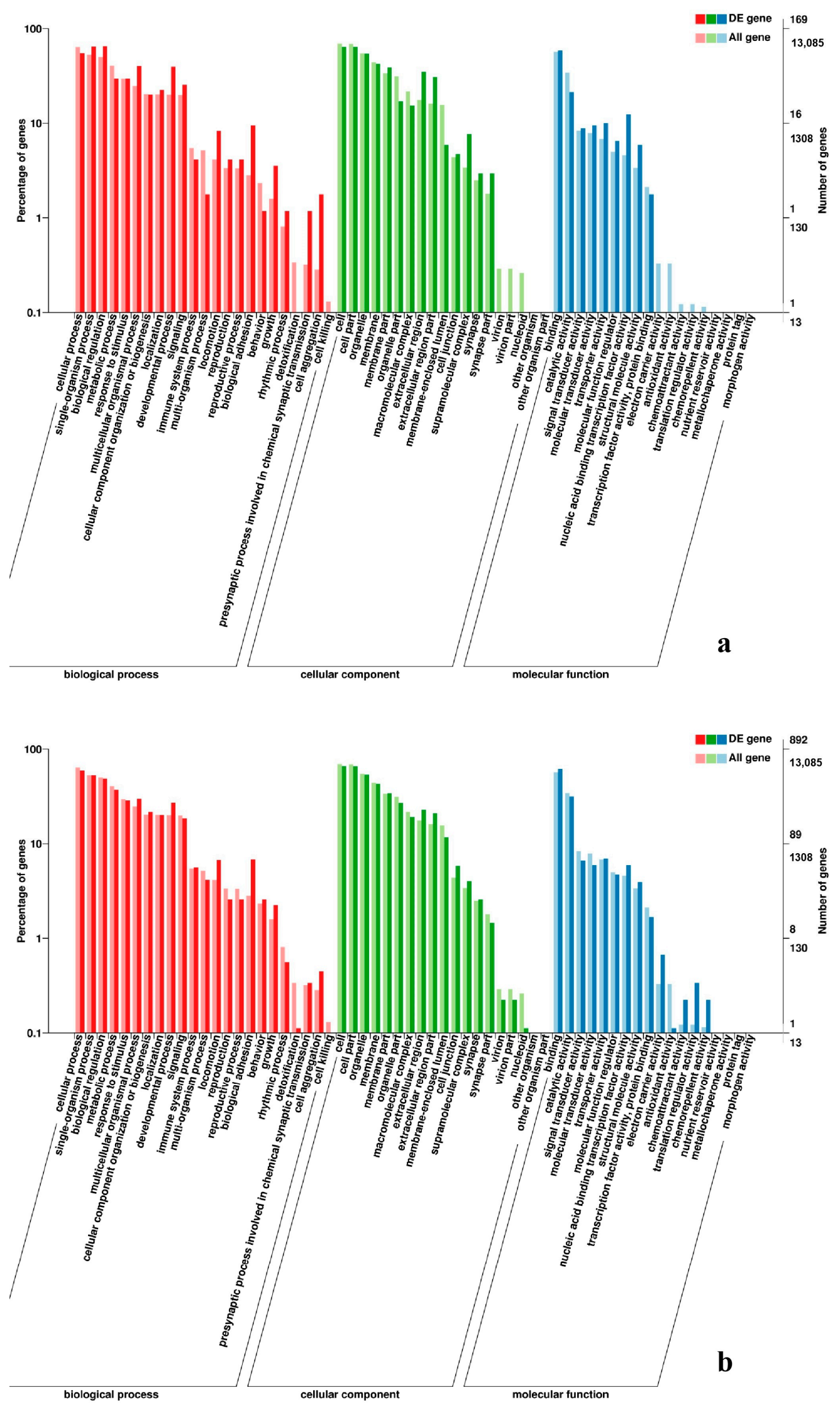

Figure 9. GO enrichment analysis of DEGs in the comparison of breast and leg muscle. (a) BE17B_vs_BE17L; (b) BE21B_vs_BE21L. 

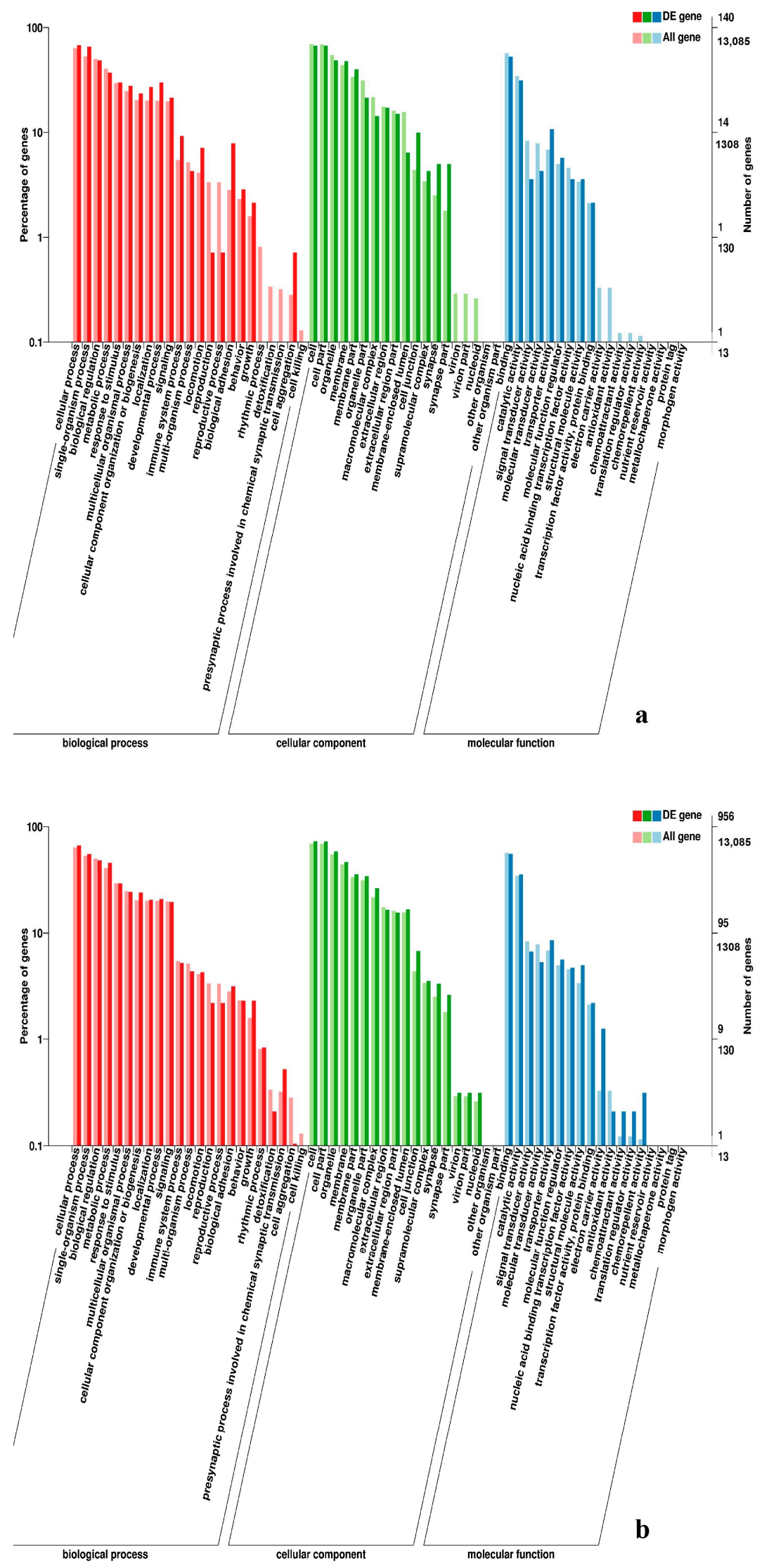

Figure 10. GO enrichment analysis of DEGs in the comparison of breast and leg muscle. (a) BE27B_vs_BE27L; (b) BE31B_vs_BE31L. 

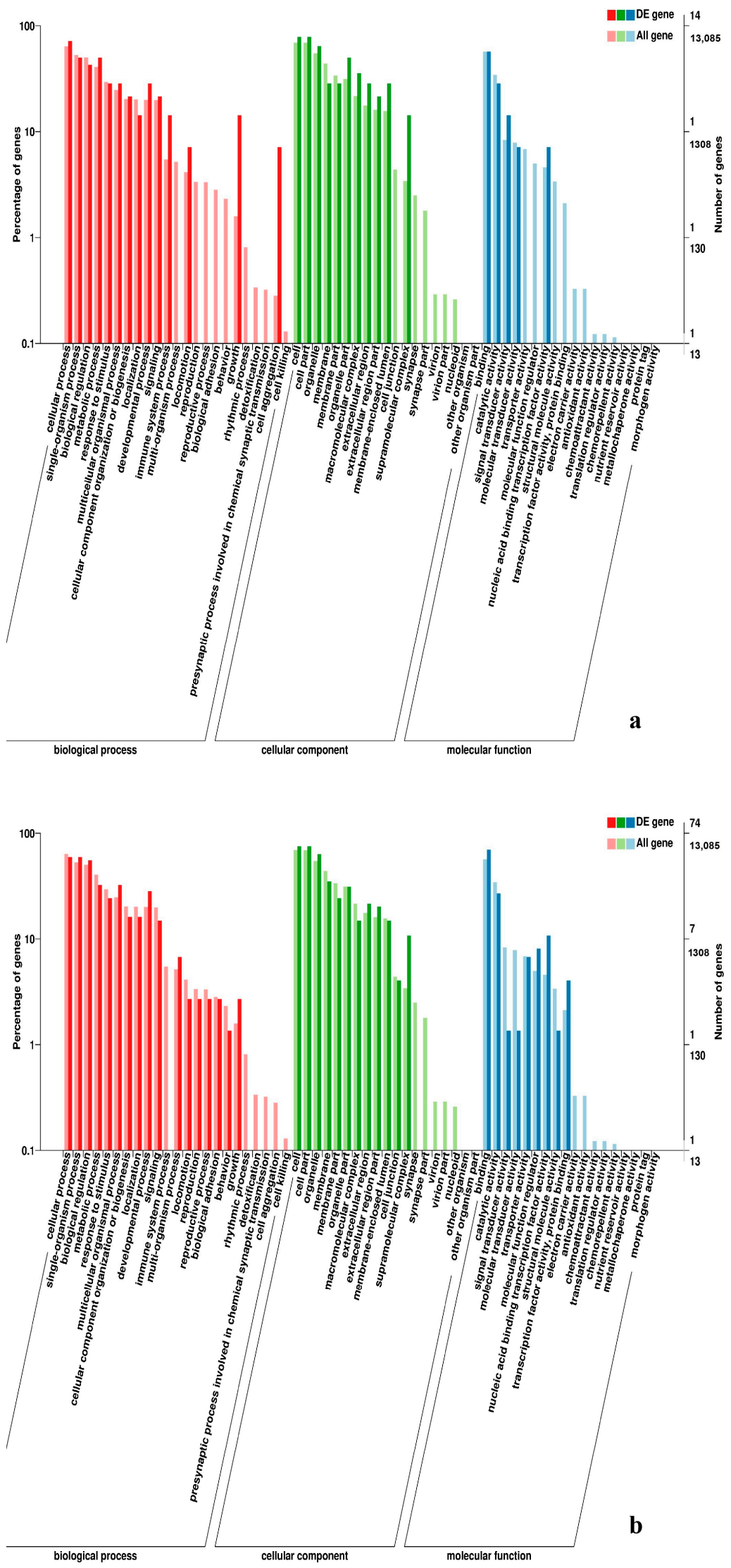

Figure 11. GO enrichment analysis of DEGs in the comparison of breast and leg muscle. (a) BE34B_vs_BE34L; (b) BM6B_vs_BM6L. 
Table 6. The most enriched GO terms.

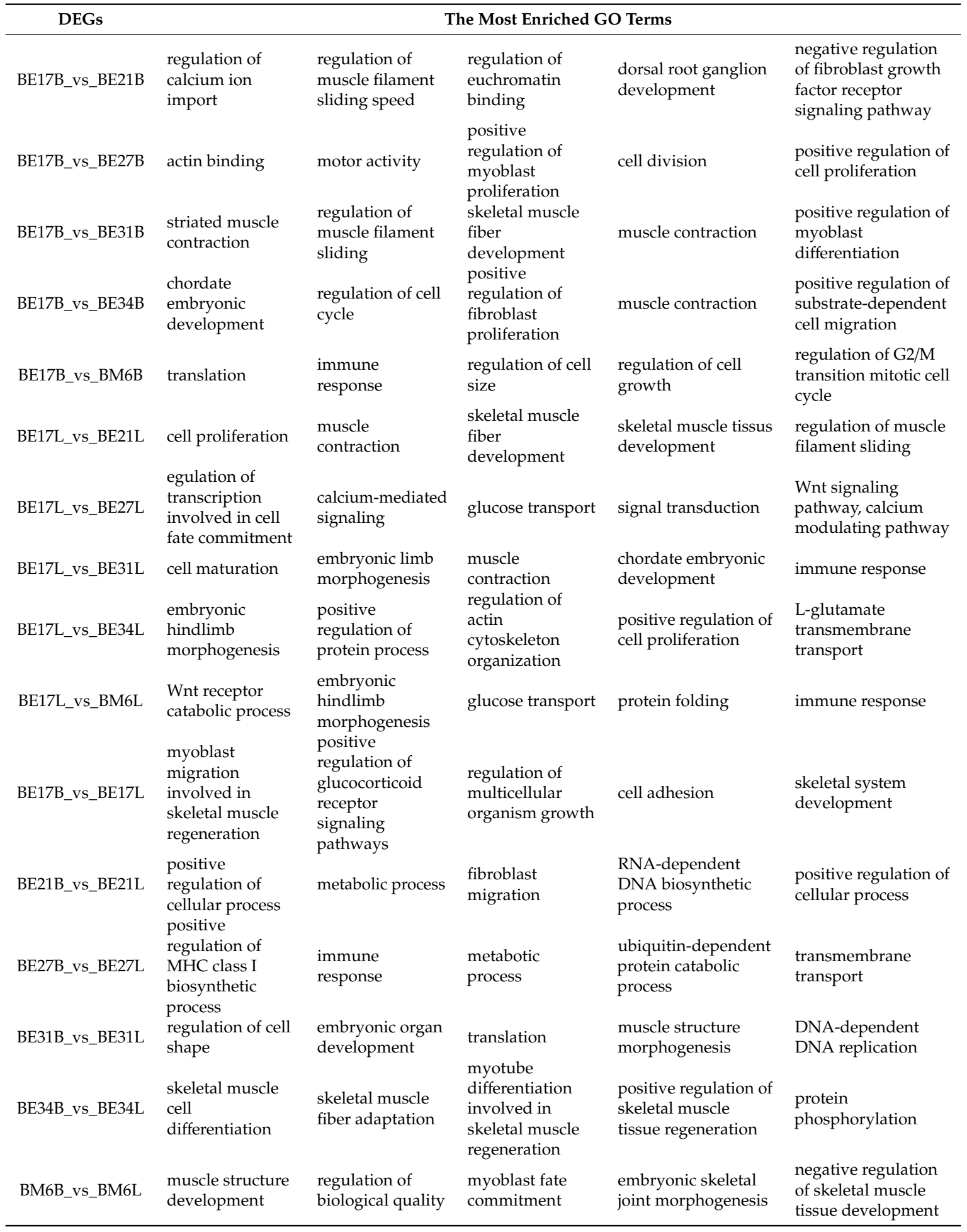



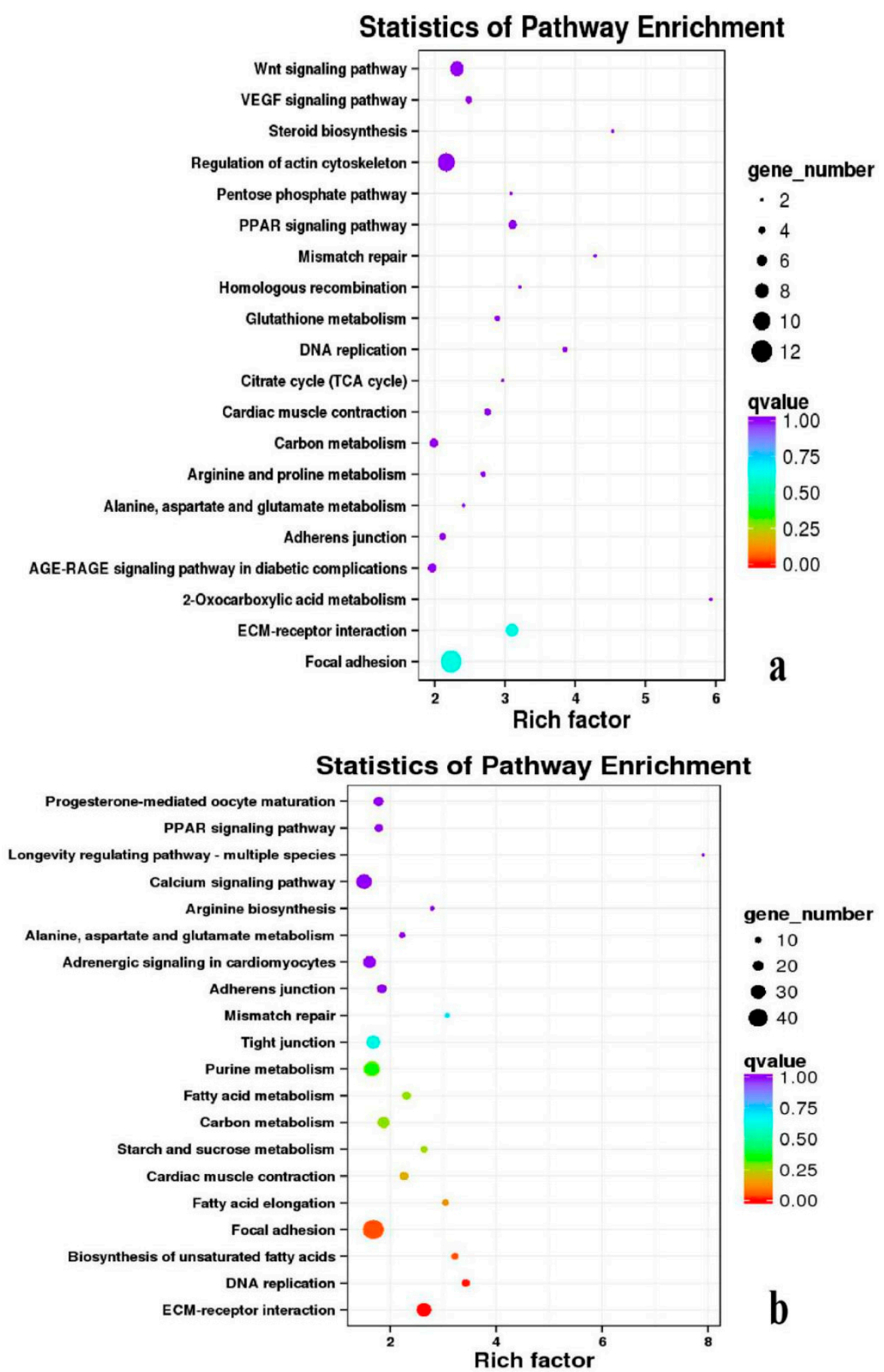

Figure 12. KEGG annotation of DEGs in breast muscle. (a) BE17B_vs_BE21B; (b) BE17B_vs_BE27B. Note: In the figure, each circle represented a KEGG pathway, name of which was shown on the left legend. Abscissa was enrichment factors, showing the proportion of (a) to (b), (a) was the ration of differentially expressed genes in the pathway with all DEGs in all pathways, (b) was the ration of genes in the pathway with all genes in all pathways. The bigger the Rich factor is, the more significant the pathway is. The color of circle represented $q$ value which is adjusted $p$ value by multiple hypothesis testing. Thus, the smaller the q value is, the more significant the pathway is; the circle size represented the number of differentially expressed genes annotated with the pathway, the bigger circle size is, the higher number of genes is. The same below. 

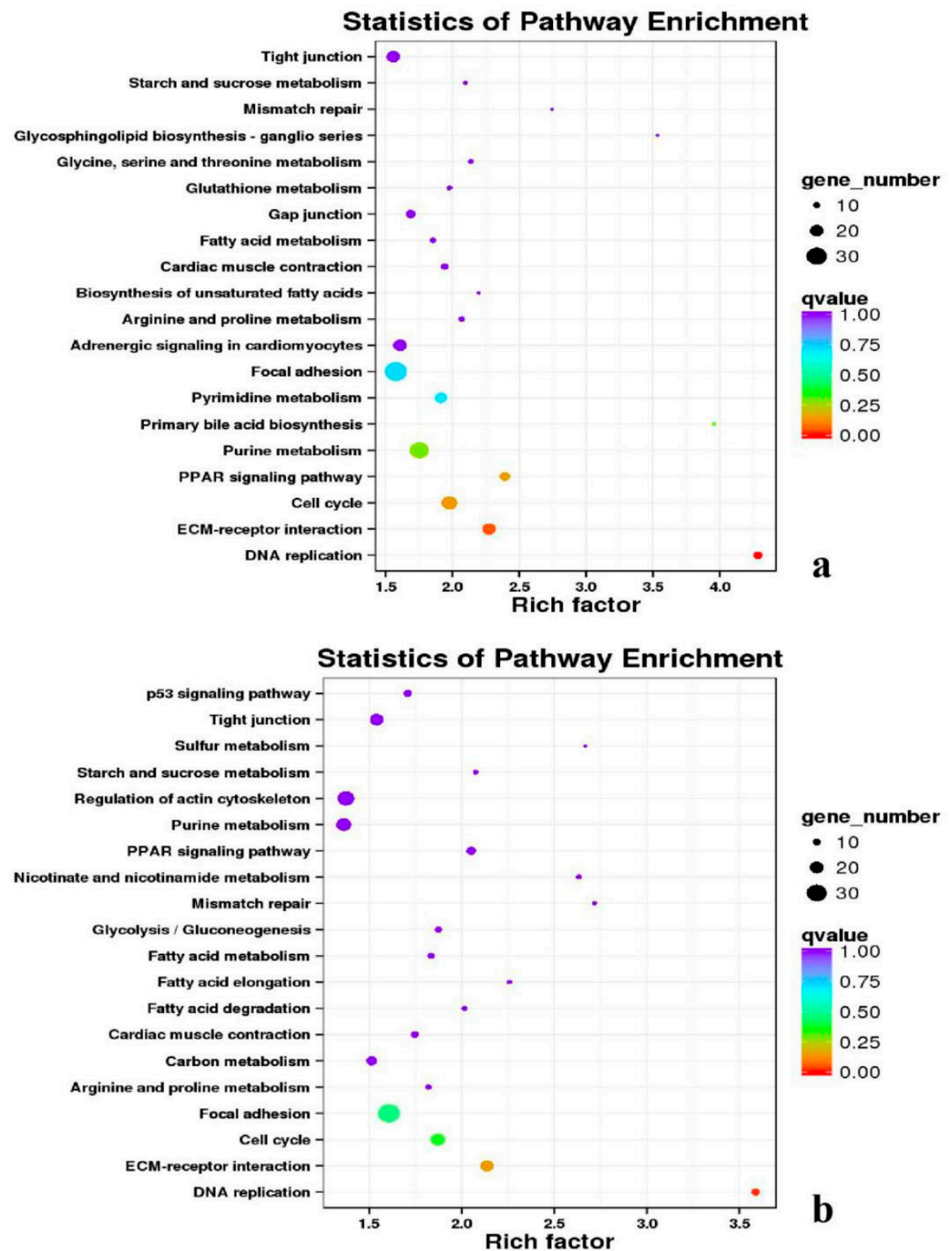

Figure 13. KEGG annotation of DEGs in breast muscle. (a) BE17B_vs_BE31B; (b) BE17B_vs_BE34B. 


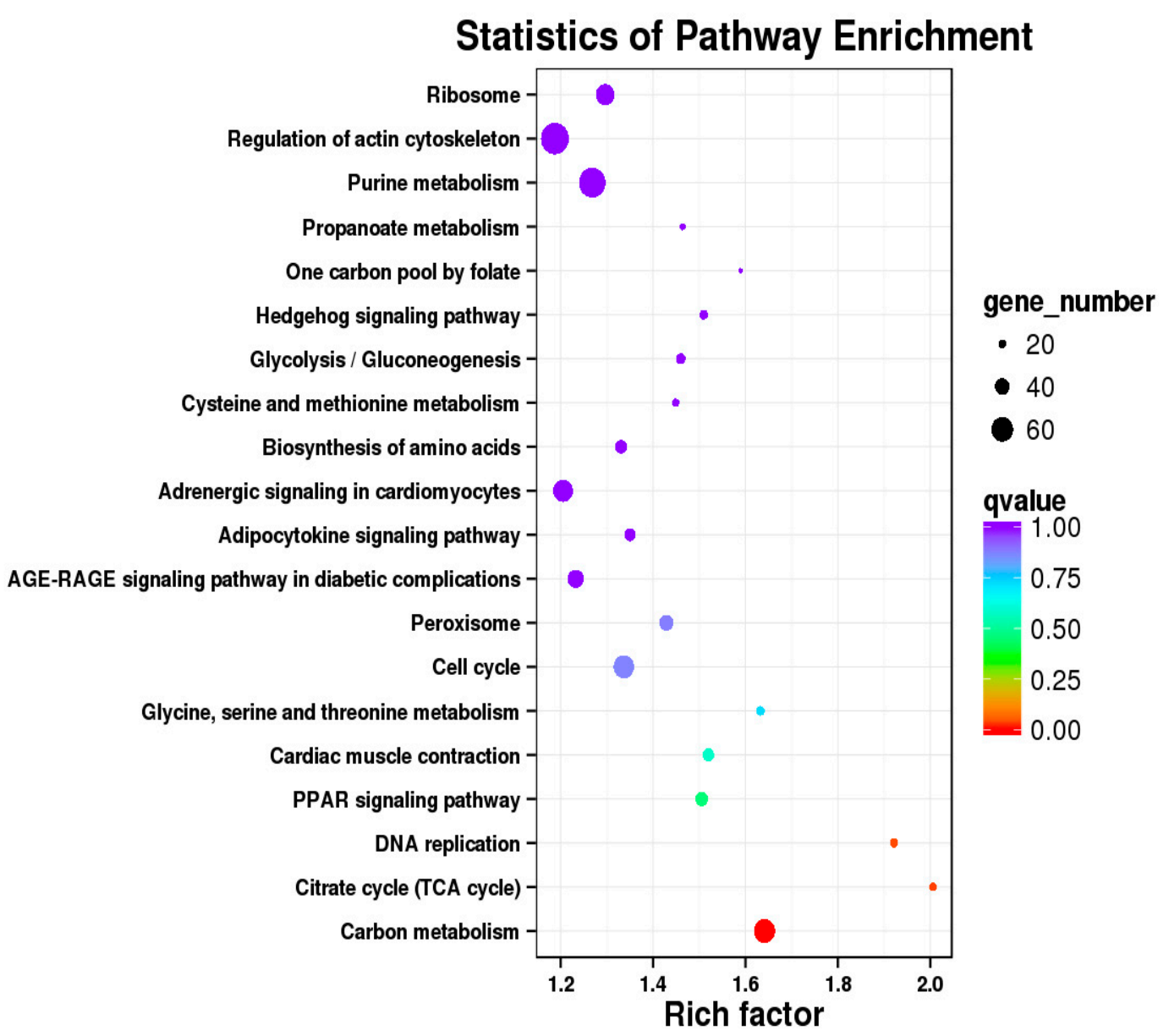

Figure 14. KEGG annotation of DEGs in breast muscle of BE17B_vs_BM6B. 
Statistics of Pathway Enrichment
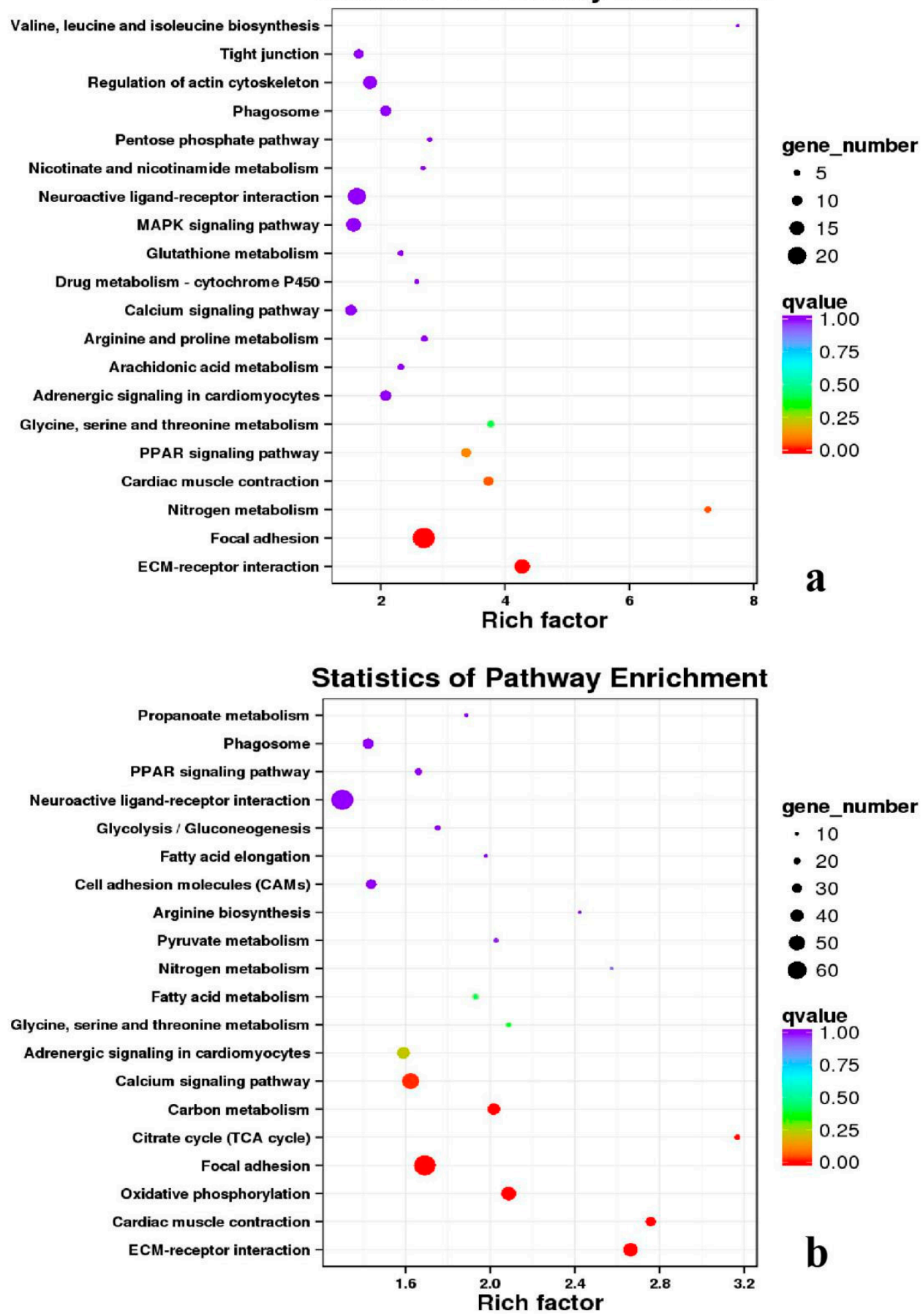

Figure 15. KEGG annotation of DEGs in leg muscle. (a) BE17L_vs_BE21L; (b) BE17L_vs_BE27L. 

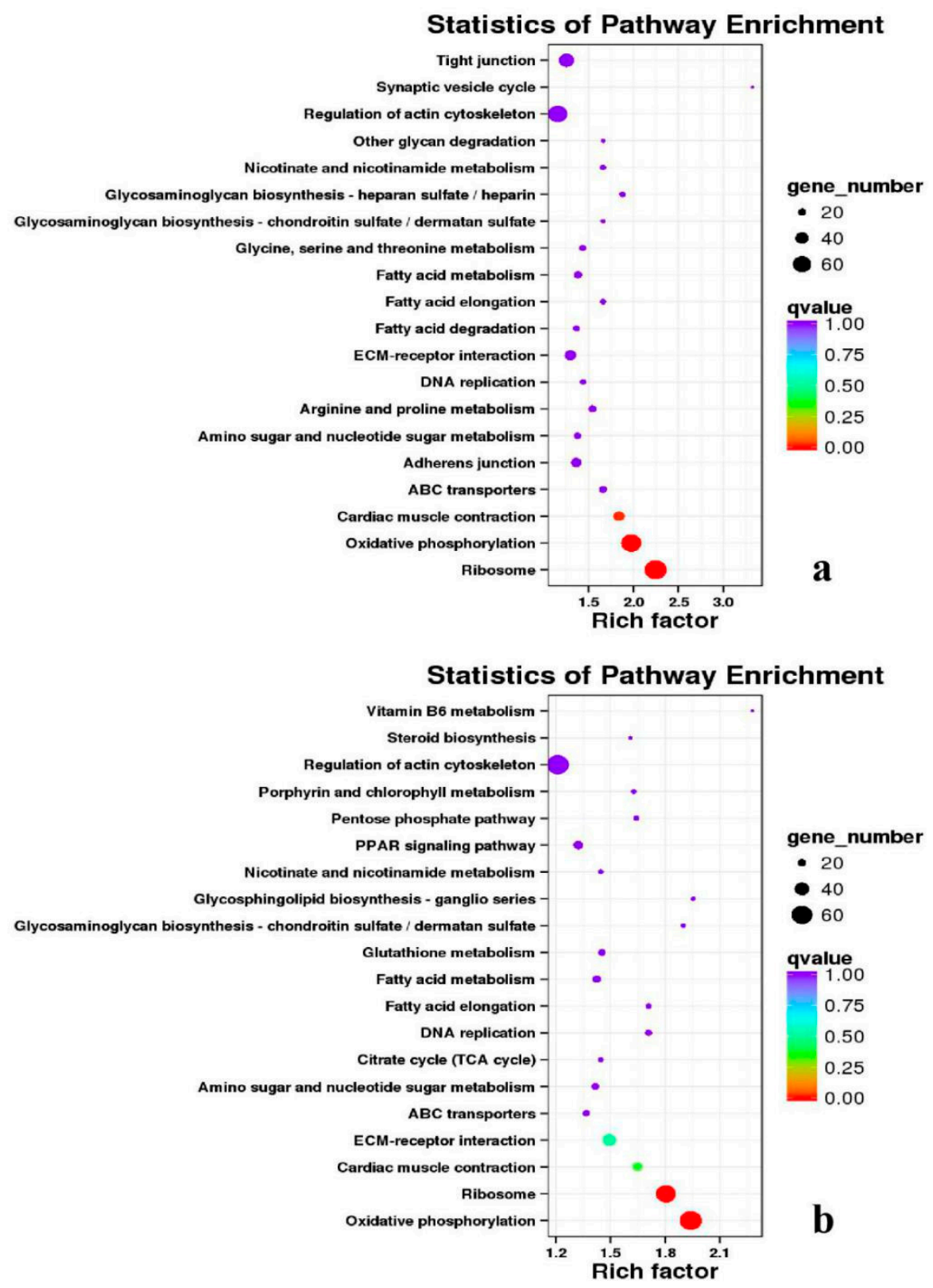

Figure 16. KEGG annotation of DEGs in leg muscle. (a) BE17L_vs_BE31L; (b) BE17L_vs_BE34L. 


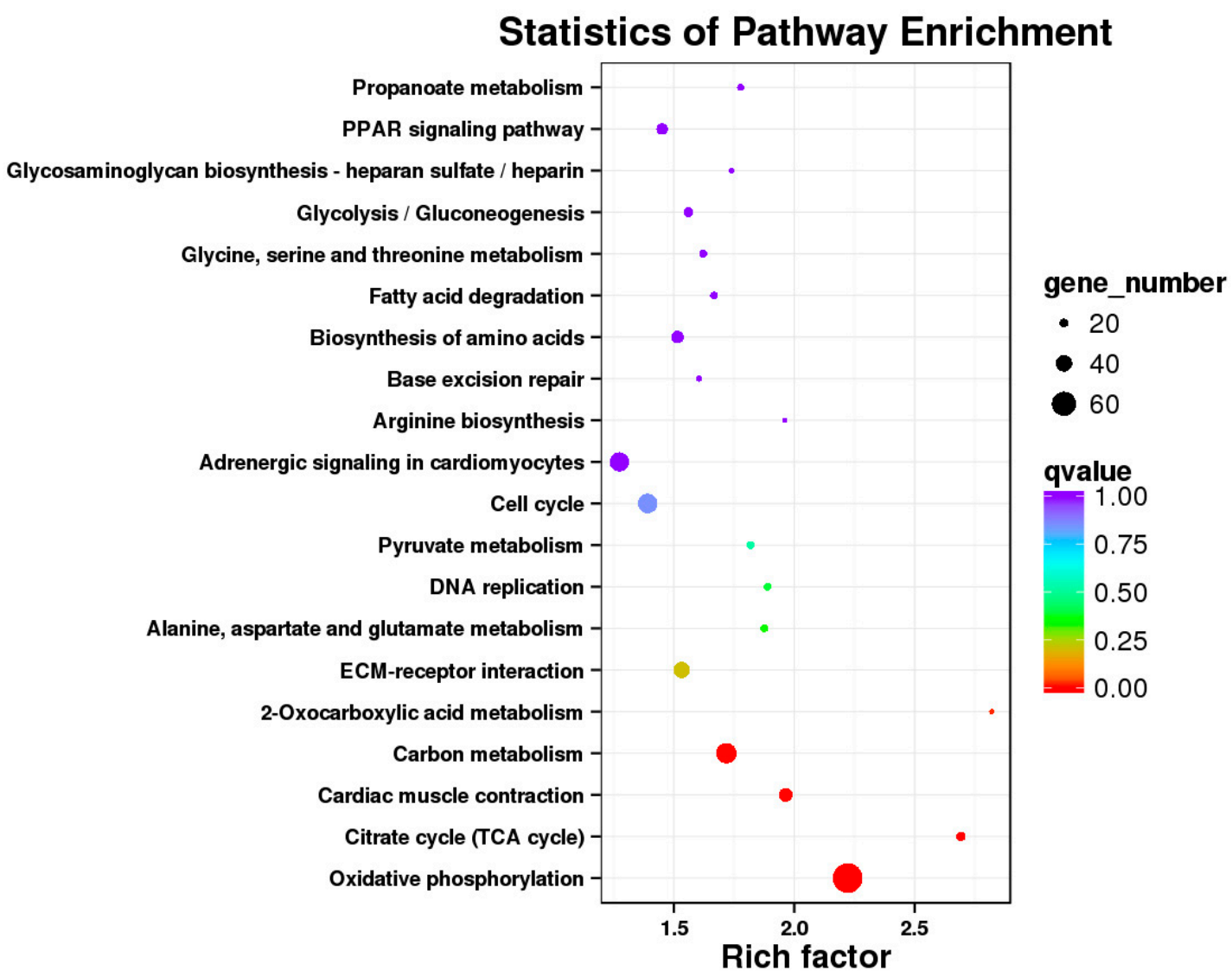

Figure 17. KEGG annotation of DEGs in leg muscle of BE17L_vs_BM6L. 


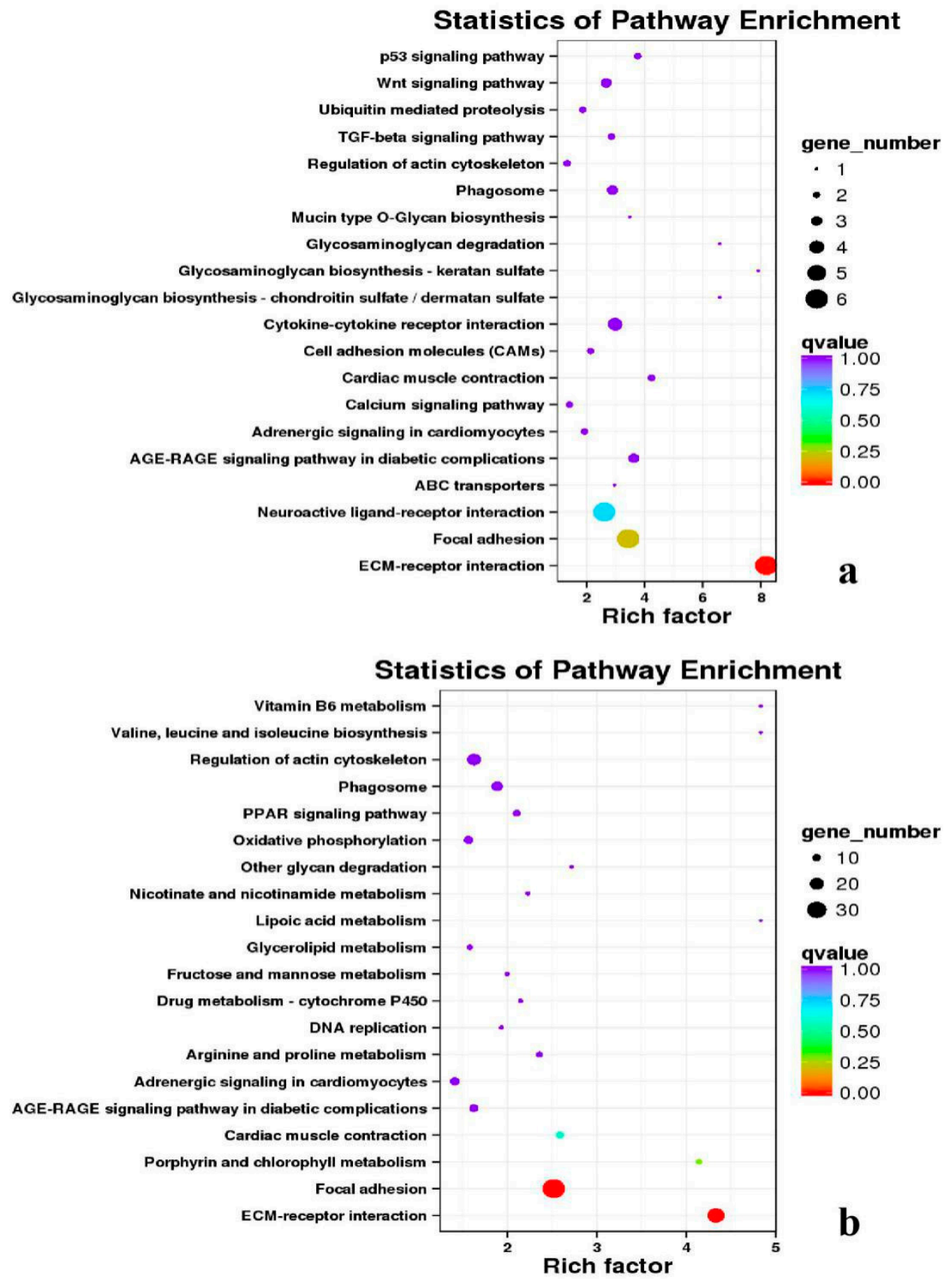

Figure 18. KEGG annotation of DEGs in the comparison of breast and leg muscle. (a) BE17B_vs_BE17L; (b) BE21B_vs_BE21L. 

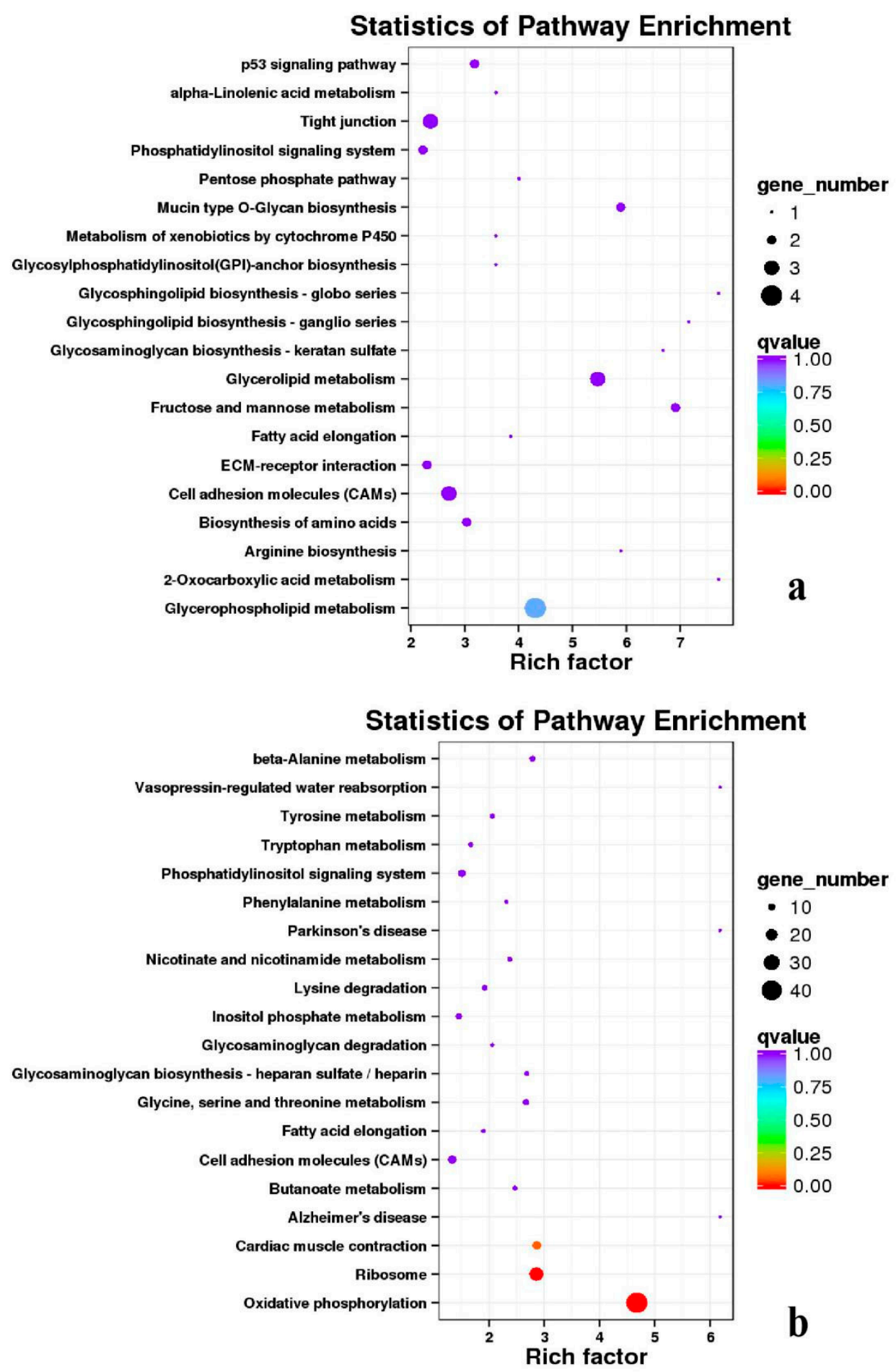

Figure 19. KEGG annotation of DEGs in the comparison of breast and leg muscle. (a) BE27B_vs_BE27L; (b) BE31B_vs_BE31L. 

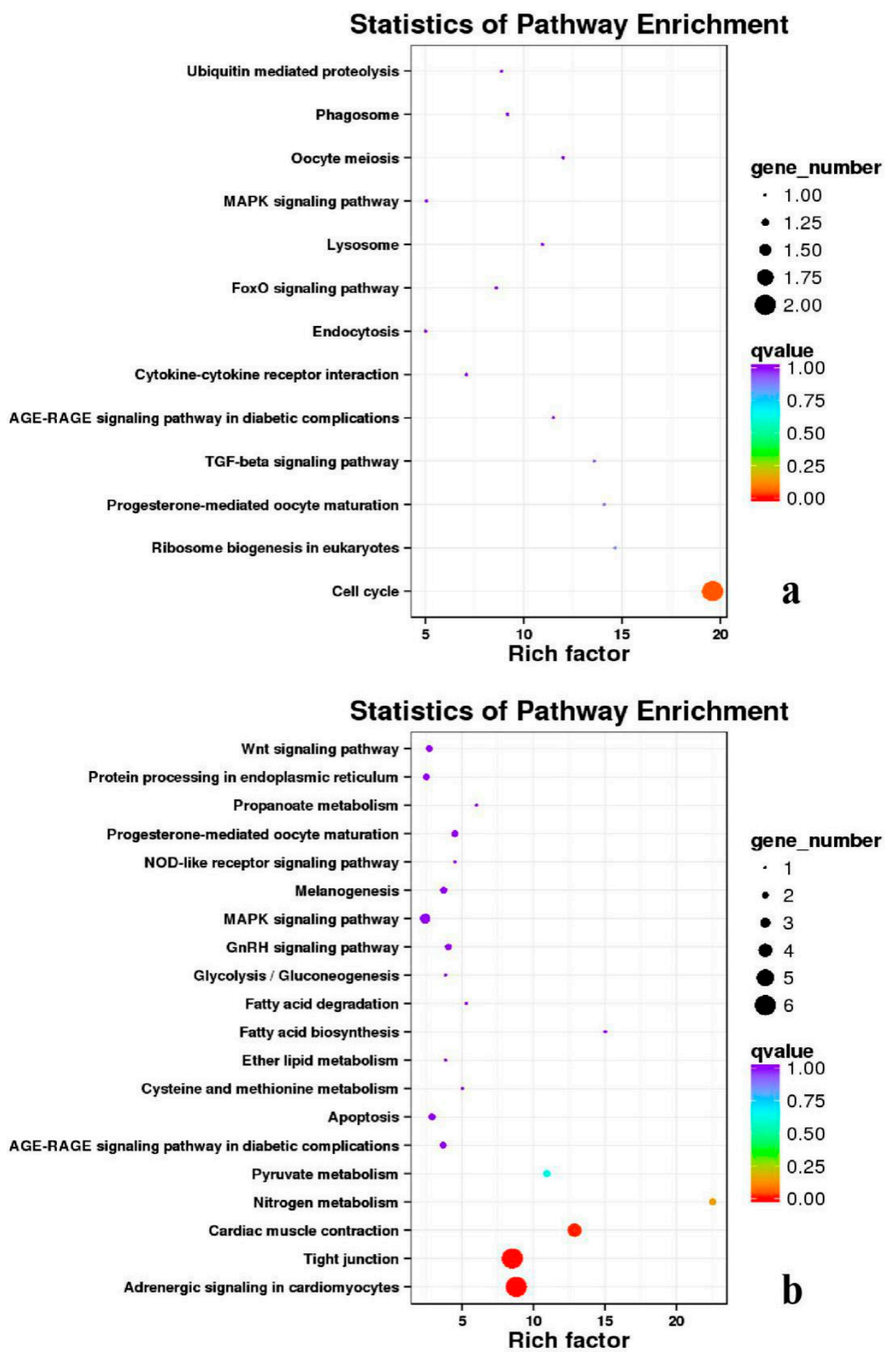

Figure 20. KEGG annotation of DEGs in the comparison of breast and leg muscle. (a) BE34B_vs_BE34L; (b) BM6B_vs_BM6L.

\section{6. qPCR Analysis}

To confirm RNA-seq data, 26 genes of duck breast and leg muscle obtained at different growth stages were selected for qPCR analysis, respectively. The expression tendency of these genes agreed well with RNA-seq results, which suggested that RNA-seq results were pretty reliable (Figure 21). 
Table 7. Top 5 of KEGG enrichment.

\begin{tabular}{|c|c|c|c|c|c|}
\hline DEGs & & & KEGG Enrichment & & \\
\hline BE17B_vs_BE21B & Focal adhesion & $\begin{array}{l}\text { Regulation of actin } \\
\text { cytoskeleton }\end{array}$ & MAPK signaling pathway & Wnt signaling pathway & ECM-receptor interaction \\
\hline BE17B_vs_BE27B & Focal adhesion & $\begin{array}{l}\text { Neuroactive ligand-receptor } \\
\text { interaction }\end{array}$ & Purine metabolism & MAPK signaling pathway & Calcium signaling pathway \\
\hline BE17B_vs_BE31B & Focal adhesion & MAPK signaling pathway & Purine metabolism & Cell cycle & Calcium signaling pathway \\
\hline BE17B_vs_BE34B & Focal adhesion & MAPK signaling pathway & $\begin{array}{c}\text { Neuroactive ligand-receptor } \\
\text { interaction }\end{array}$ & $\begin{array}{l}\text { Regulation of actin } \\
\text { cytoskeleton }\end{array}$ & Endocytosis \\
\hline BE17B_vs_BM6B & $\begin{array}{l}\text { Leukocyte } \\
\text { transendothelial } \\
\text { migration }\end{array}$ & Thiamine metabolism & ErbB signaling pathway & Glucagon signaling pathway & $\begin{array}{l}\text { RIG-I-like receptor signaling } \\
\text { pathway }\end{array}$ \\
\hline BE17L_vs_BE21L & Focal adhesion & $\begin{array}{c}\text { Neuroactive ligand-receptor } \\
\text { interaction }\end{array}$ & ECM-receptor interaction & MAPK signaling pathway & $\begin{array}{l}\text { Regulation of actin } \\
\text { cytoskeleton }\end{array}$ \\
\hline BE17L_vs_BE27L & $\begin{array}{l}\text { Neuroactive } \\
\text { ligand-receptor } \\
\text { interaction }\end{array}$ & Focal adhesion, & Calcium signaling pathway & MAPK signaling pathway & Oxidative phosphorylation \\
\hline BE17L_vs_BE31L & Ribosome & Focal adhesion & Oxidative phosphorylation & MAPK signaling pathway & $\begin{array}{l}\text { Regulation of actin } \\
\text { cytoskeleton }\end{array}$ \\
\hline BE17L_vs_BE34L & Focal adhesion & $\begin{array}{l}\text { Neuroactive ligand-receptor } \\
\text { interaction }\end{array}$ & $\begin{array}{l}\text { Regulation of actin } \\
\text { cytoskeleton }\end{array}$ & Oxidative phosphorylation & MAPK signaling pathway \\
\hline BE17L_vs_BM6L & $\begin{array}{l}\text { Neuroactive } \\
\text { ligand-receptor } \\
\text { interaction }\end{array}$ & MAPK signaling pathway & Oxidative phosphorylation & Focal adhesion & Calcium signaling pathway \\
\hline BE17B_vs_BE17L & Focal adhesion & $\begin{array}{c}\text { Neuroactive ligand-receptor } \\
\text { interaction }\end{array}$ & ECM-receptor interaction & $\begin{array}{c}\text { Cytokine-cytokine receptor } \\
\text { interaction }\end{array}$ & Phagosome \\
\hline BE21B_vs_BE21L & Focal adhesion & ECM-receptor interaction & $\begin{array}{l}\text { Regulation of actin } \\
\text { cytoskeleton }\end{array}$ & Phagosome & $\begin{array}{c}\text { Neuroactive ligand-receptor } \\
\text { interaction }\end{array}$ \\
\hline BE27B_vs_BE27L & $\begin{array}{l}\text { Glycerophospholipid } \\
\text { metabolism }\end{array}$ & Glycerolipid metabolism & Tight junction & $\begin{array}{l}\text { Cell adhesion molecules } \\
\text { (CAMs) }\end{array}$ & Biosynthesis of amino acids \\
\hline BE31B_vs_BE31L & $\begin{array}{c}\text { Oxidative } \\
\text { phosphorylation }\end{array}$ & Ribosome & $\begin{array}{l}\text { Regulation of actin } \\
\text { cytoskeleton }\end{array}$ & Calcium signaling pathway & MAPK signaling pathway \\
\hline BE34B_vs_BE34L & Cell cycle & Endocytosis & MAPK signaling pathway & $\begin{array}{c}\text { Cytokine-cytokine receptor } \\
\text { interaction }\end{array}$ & $\begin{array}{l}\text { Ubiquitin mediated } \\
\text { proteolysis }\end{array}$ \\
\hline BM6B_vs_BM6L & $\begin{array}{l}\text { Adrenergic signaling in } \\
\text { cardiomyocytes }\end{array}$ & Tight junction & Cardiac muscle contraction & MAPK signaling pathway & Apoptosis \\
\hline
\end{tabular}



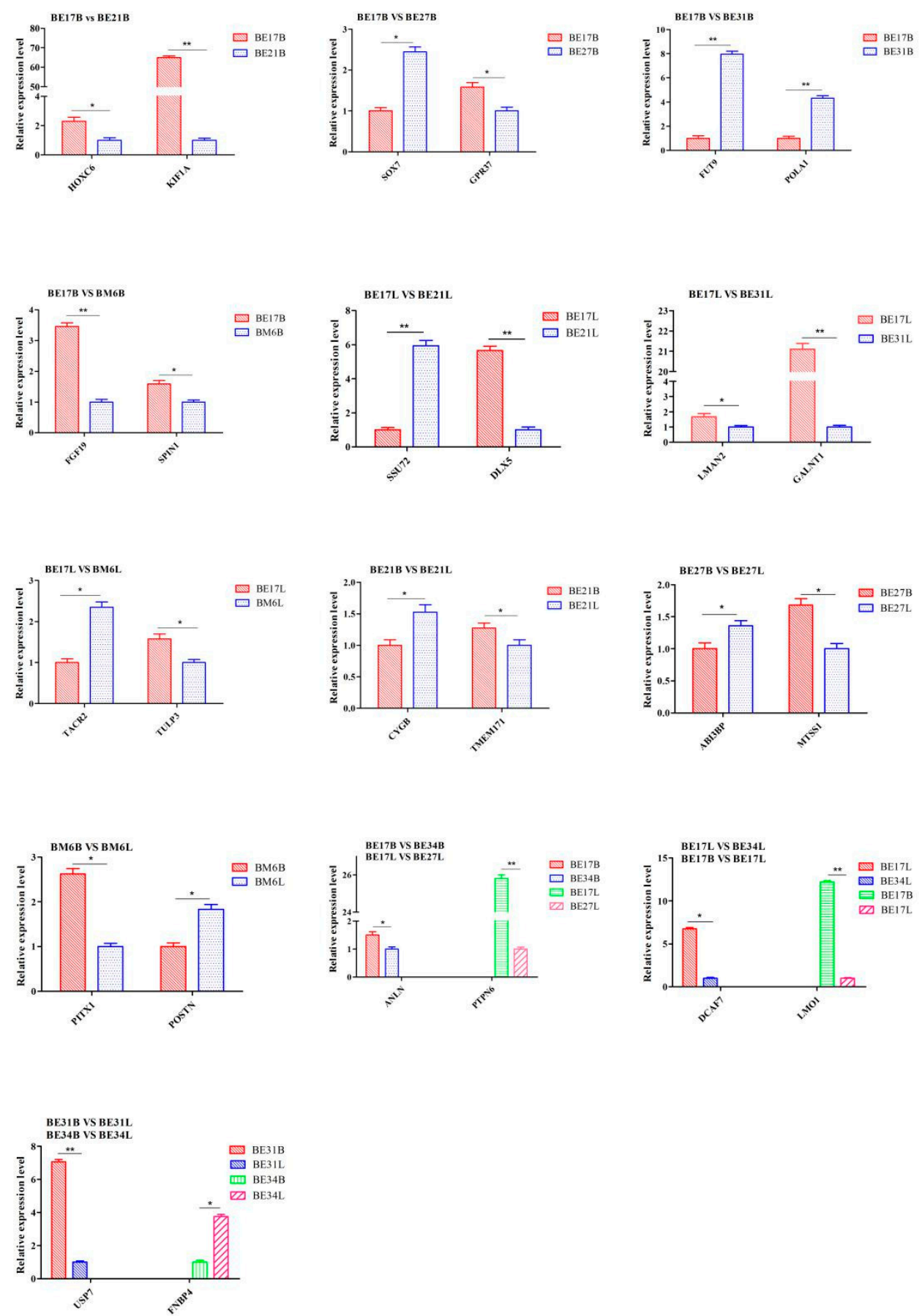

Figure 21. qPCR verification of DEGs. "** was considered significant difference $(p<0.05)$; “**” was considered extremely significant difference $(p>0.01)$.

\section{Discussion}

Duck growth performance, mainly skeletal muscle growth, provides direct economic benefits to the poultry industry. However, the underlying genetic mechanisms remain unclear. The purpose of this study was to identify candidate genes associated with the growth of duck skeletal muscle and investigate their potential mechanisms. Transcriptome analysis is an efficient and fast tool that has been widely used in animal husbandry. Comparative transcriptome analyses of tissues at different developmental stages provide valuable insights into the question of how regulatory gene 
networks control specific biological processes $[18,19]$. In this study, we focus on the skeletal muscle tissue of black Muscovy duck, because it is the prime part of carcass, and the yield of breast and leg meat is one of practical importance to the profitability of production [20]. Besides, muscle fiber numbers increase during embryonic development in poultry, after which myofiber numbers stop to increase, while myofiber volume still increases [8]. Therefore, we studied the gene expression patterns and network pathways at different developmental stages to further understand the molecular mechanism of duck skeletal muscle development. Annotation of the sequence data using the duck genome as a reference revealed expression of 39,401,532 to $66,211,580$ genes in the duck skeletal muscle transcriptome, and an average of $49,119,720$ high-quality reads per sample were mapped to the Ap genome.

\subsection{SNP/InDel Analysis}

RNA-seq measures not only gene expression, but also structural variations such as fusion transcriptions or mutations. SNP, a type of genome polymorphisms, only involves the variation of a single base. Because SNPs are abundant and have greater stability over generations, genotyping more accurately and easily automates the genotyping processes [21]. Some studies have reported a large number of SNPs associated with animal weight and muscle development traits. These candidate genes could be used as molecular markers in early marker-assisted selection in animal breeding programs [22,23]. InDels are a major class of genomic variation, which are primarily detected from DNA-seq data $[24,25]$. In order to explore the gene SNPs and InDels related to muscle growth and development, gene levels of the breast and leg muscle tissues were analyzed by high throughput RNA sequencing technology. There were 23,381 to 634,028 SNPs in skeletal muscles at different growth stages, where total numbers of SNPs in the genic region were 20,572 to 574,484 , total numbers of SNPs between genes were 2809 to 59,544. The most common change was G/A and C/T, followed by $\mathrm{A} / \mathrm{G}$ and T/C. The annotations of SNP were mainly distributed in "INTRON" (2,898,440 for breast muscle and 2,103,619 for leg muscle), "SYNONYMOUS_CODING" (1,319,429 for breast muscle and 1,395,604 for leg muscle) and “UTR_3_PRIME" (1,031,194 for breast muscle and 1,050,568 for leg muscle). The annotations of InDels were mainly distributed in "INTRON" (184,929 for breast muscle and 123,569 for leg muscle), "UTR_3_PRIME" (143,626 for breast muscle and 140,766 for leg muscle) and "DOWNSTREAM" (35,847 for breast muscle and 31,447 for leg muscle), indicating that the skeletal muscle SNPs and InDels of black Muscovy ducks at different growth stages were mainly in "INTRON", "SYNONYMOUS_CODING", “UTR_3_PRIME", and "DOWNSTREAM". Inclusion of SNPs and InDels (many of which may be located in genes) in annotated genes will provide a large number of gene centric markers, which will add detailed information for the genetic loci for specific phenotypic traits.

\subsection{Prediction of $A S$}

AS is a ubiquitous in most eukaryotic genomes, which is a mechanism for organisms to increase their protein pool and regulate physiological and developmental processes/pathways [26-28]. Precursor mRNA of AS plays an important role in the regulation of gene expression in higher eukaryotes. Multiple mRNAs can be derived from a single pre mRNA to produce proteins with different functions, which indicates that AS is an important mechanism for regulating life [29]. Isoform expression patterns may provide unique insights into the skeletal muscle transcriptome since it is likely that unique transcript splice variants may play essential roles during development [30]. Due to the lack of detailed full-length cDNA data and high-quality genome annotation, there are few studies about AS in ducks or other birds [31,32]. Yin et al. (2019) found that a total of 199,993 full-length transcripts were obtained from 8 duck tissues by using transcriptome sequencing, and 35,031 AS events were accurately predicted from 3346 genes, which is very useful for the functional research of other birds [33]. In our study, an average of 37,267 AS events were counted from each sample, and the number of AS in each sample were mainly concentrated in TSS and TTS, which indicated that the AS of duck skeletal muscle growth and development mainly existed in the first exon and the last exon. 


\subsection{DEGs Analyzed at All Time Points}

The differential expression of growth related genes is considered to be the main cause of genetic variation during duck growth and development, indicating that the regulatory mechanism of growth has changed [13]. In our study, at different time points, the skeletal muscle of black Muscovy duck had 19 to 5377 DEGs. It was worth noting that there were only 19 DEGs in BE34B_vs_BE34L. It is speculated that the genes that regulate the proliferation and differentiation of duck breast and leg muscle were basically the same at this time. It is well known that these processes involved by the DEGs at different developmental stages are essential for maintaining animal muscle growth. Therefore, these genes may play an important role in growth and development of duck skeletal muscle. Further functional studies with these DEGs were warranted to identify key genes influencing muscle growth and development of duck. Besides, some DEGs were found to be closely related to growth and development of skeletal muscle in black Muscovy duck, including transcription factors such as MyoG, FBXO1, MEF2A, and FoxN2, as well as a series of genes related to muscle growth axis, such as FAF1, RGS8, GRB10, SMYD3, and TNNI2. Moreover, some studies have shown that these regulatory transcription factors interacted with each other in regulating animal muscle growth.

Fas-associated factor 1 (FAF1) is involved in diverse bio-chemical processes including cell death, inflammation, cell proliferation, and proteostasis [34]. FAF1 mediates caspase-8 activation via both

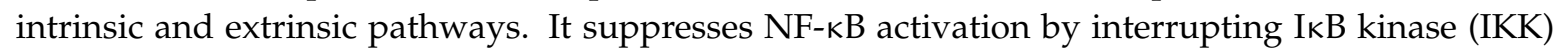
complex assembly, and promotes Fas-induced apoptosis [35,36]. FAF1 also inhibits cell cycle by negatively regulating Aurora-A. Moreover, FAF1 regulates the polyubiquitinated protein and valosin containing protein, and inhibits the degradation of ubiquitin dependent proteins [37,38]. Studies have shown that FAF1 antagonized Wnt signal transduction by promoting the degradation of $\beta$-Catenin [39]. Wnts regulate cell proliferation and differentiation, and control many biological processes including embryonic development $[40,41]$. FAF1 regulates $W n t / \beta$-Catenin dependent gene expression in C2C12 myoblasts, including genes involved in osteoblast differentiation [39]. FAF1 is necessary for early embryogenesis. Adham et al. (2008) found that FAF1 gene targeted mice showed embryonic lethality at the two cell stage [42]. Ryu et al. (1999) found Human FAF1 mRNA is abundantly expressed in testis, skeletal muscle, and heart [43]. Fröhlich et al. (1998) identified the avian FAF1 homologue (qFAF) in the pluripotent cells from E0 quail embryos during mesoderm induction in vitro by using mRNA differential display technique, which can be used as the induction gene of fibroblast growth factor (FGF) [44]. Therefore, FAF1 may play an important role in the development of duck skeletal muscle.

Regulator of G protein signaling proteins (RGS) are negative modulators of many G-Protein Coupled Receptor (GPCR) signaling pathways [45]. RGS protein directly binds to the G $\alpha$ subunit of GTP of activated heterotrimer G protein, which increases the rate of GTP hydrolysis [46]. By this mechanism, RGS proteins rapidly dampen GPCR signal transduction at the level of the active G protein subunits [47]. Regulator of G protein signaling 8 (RGS8) belongs to the R4 subfamily of RGS proteins, and modulates the functioning of G-proteins by activating the intrinsic GTPase activity of the a subunits $[48,49]$. RGS is involved in many intracellular processes mediated by G protein signal transduction pathway, including cell proliferation, cell differentiation, plasma membrane transport, cell movement, and embryonic development [50]. In our study, RGS8 may regulate G protein by activating GTPase activity of a subunit and participate in development of duck skeletal muscle.

Growth factor receptor-bound protein 10 (GRB10) regulates phosphorylation and activation of the mTORC1 protein, which is a central regulator of cellular metabolism, growth and survival [51,52]. GRB10 is also involved in the regulation of glucose metabolism during fetal and postnatal period [53]. It is also one of the participants in ensuring the metabolic health of fetus to adult. GRB10 binds to Gab1 and participates in the regulation of cell mitosis [54]. Besides, GRB10 is an adaptor protein, which interacts with a number of receptor tyrosine kinases and signaling molecules [55]. GRB10 associates with a variety of growth factors at the cell surface, such as the insulin growth factor receptor (IGFR), and with intracellular protein kinases like Raf1 and MEK1 [56,57]. It is a negative regulator of IGFIR-dependent cell proliferation, and plays a negative regulatory role in the MAPK 
signaling pathway [58,59]. Notably, IGF and MAPK signaling pathway play an important role in skeletal muscle development. Studies have shown that GRB10 is abundant in brain, fat, muscle and heart of mice [60]. Mutation of GRB10 induces muscle hypertrophy in mice [61], and the embryos and placentas of mice lacking GRB10 were overgrown, such that mutant mice were $30 \%$ larger than normal at birth [55]. It was suggested that GRB10 may be very important for skeletal muscle development in duck.

Muscle fibers are composed of myofibrils, and members of the SMYD family play critical roles in myofibril assembly of skeletal and cardiac muscle during development [62]. SET and MYND domain-containing protein 3 (SMYD3) is widely distributed in eukaryotes and participates in epigenetic transcription regulation, development and cell proliferation [63]. SMYD3 is also necessary for regulating skeletal muscle and myocardial development [64]. SMYD3 controls skeletal muscle development and maintenance through transcriptional regulation [65]. Fujii et al. (2011) found that in zebrafish embryos, SMYD3-knockdown led to abnormal expression of myogenic markers including $M y o D$, which indicated that SMYD3 may play a role in muscle development [64]. In addition, SMYD3 is involved in regulating skeletal muscle atrophy. During the process of dexamethasone-induced skeletal muscle atrophy, the mRNA level of $S M Y D 3$ was significantly increased [66]. The differential expression of SMYD3 in duck may be related to greater myogenic potential. Troponin I2 (TNNI2), a muscle growth marker gene [67,68], encodes a subunit of troponin complex [69], which are expressed under muscle type-specific and developmental regulations [70]. Troponin complex is a group of muscle proteins, which is part of the contraction device of rapid skeletal muscle contraction [71]. In the absence of $\mathrm{Ca}^{2+}$, TNNI2 prevents muscle contraction by binding actin and tropomyosin [72]. Besides, Yoshimoto et al. (2020) found that expression of TNNI2 was gradually increased as muscle regeneration proceeds, indicating that TNNI2 were excellent indicator to assess myofiber maturity [73]. TNNI2 encodes an isoform of TnI specific to fast-twitch myofibers and troponin I (TnI) mutation with abnormal skeletal muscle structure leads to wing and limb defects in Drosophila [74]. Besides, the expression of slow-twitch $T n I$ is stronger in soleus muscle, while the expression of fast-twitch $T n I$ is stronger in tibial anterior muscle and extensor digitorum longus in neonatal mice [75]. Therefore, TNNI2 may be an interesting candidate gene to explain the phenotypic differences of skeletal muscle development in duck.

The RNA-Seq data were confirmed to be reliable by qPCR. These identified DEGs included many genes significantly related to muscle development.

\subsection{GO and KEGG Pathway}

GO database is a structured standard biological annotation system. It aims to establish a standard system for genes and their products, which is suitable for all species. GO annotation system includes three main branches: Biological Process, Molecular Function, and Cellular Component. In this study, several key DEGs (such as MyoG, FBXO1, MEF2A, FAF1, RGS8, GRB10, SMYD3, and TNNI2) involved in muscle development can be identified in enriched GO terms, which providing a theoretical basis for the skeletal muscle development of black Muscovy duck at different growth stages. The GO analysis of these DEGs showed that the biological processes related to cell growth, muscle development, and cellular activities (such as junction, migration, assembly, differentiation, and proliferation), muscle contraction, as well as glycogen metabolic and biosynthetic processes, were regulated differently at each developmental stage, indicating that the DEGs played an important role in regulating duck skeletal muscle.

In organisms, different genes interact to perform biological functions. Annotation and analysis of pathways are helpful to further understand the functions of genes. KEGG is a database for systematic analysis of gene function and genome information, which can be used as a whole network to study gene and expression information. Duck muscle growth is a complex process influenced by multiple genes and controlled by multiple pathways. In our KEGG analysis, main pathways related to muscle growth were identified, namely, focal adhesion, ECM-receptor interaction, MAPK signaling 
pathway, neuroactive ligand-receptor interaction, endocytosis, oxidative phosphorylation, ribosome, tight junction, insulin signaling pathway, and regulation of the actin cytoskeleton, of which the focal adhesion, MAPK signaling pathway and regulation of the actin cytoskeleton were the most significantly enriched (Figures S10-S12).

Focal adhesions (FAs) are integrin-containing, multi-protein assemblies crossing the plasma membrane that connect the cellular cytoskeleton to surrounding extracellular matrix. They play a key roles in adhesion and cell signal transduction, and are the main regulators of epithelial homeostasis, tissue response to injury and tumorigenesis [76]. Focal adhesion kinase (FAK) is a multifunctional molecule with the ability to regulate muscle formation, hypertrophy and glucose metabolism [77]. The mitogen-activated protein kinase (MAPK) signaling pathway is a phosphorylation kinase signaling cascade that regulates many cell processes, such as cell division, differentiation, and release of inflammatory mediators [78]. It is well known that MAPK signaling pathway induces protein synthesis and promotes skeletal muscle growth or hypertrophy [79]. The actin cytoskeleton comprises a scaffold of polymeric actin filaments that are assembled and disassembled to organize cell architecture and direct many cell processes. The actin-related proteins control actin filaments reorganization, resulting in significant changes in actin cytoskeleton structure, thus regulating cell processes that affect mitosis, cytokinesis, endocytosis, and cell migration [80,81]. At focal adhesion, the extracellular domain of transmembrane integrin, including $\alpha$ and $\beta$ subunits, is connected to the extracellular matrix (ECM). The intracellular tail of integrin binds to connexin, and connexin binds to the actin cytoskeleton to perform their related functions [82]. Therefore, the results of this study will allow us to predict the function of new genes and to explore candidate genes that might play a role in muscle growth and development process in duck. Besides, the annotation findings of the current investigation can be used as the selection marker for the genes related to the skeletal muscle growth and might be helpful in better understanding of genetic mechanisms associated with the growth of duck skeletal muscle.

\section{Conclusions}

In this study, transcriptome data was generated by RNA-Seq technology, which will help to further understand the molecular sequences and functions of skeletal muscle growth related genes of black Muscovy duck at different stages. There were differences in the expression of genes at different growth stages, including SNPs, InDels, AS, highly expressed genes and pathways. These findings will provide valuable resources for the biological researches of skeletal muscle growth related genes in black Muscovy duck and may also provide clues for understanding the molecular mechanisms in other poultry and mammalian species.

Supplementary Materials: The following are available online at http://www.mdpi.com/2073-4425/11/10/1228/s1, Table S1 The Concentration and RIN value of sample RNA; Table S2 Statistics of sequence comparison between sample sequencing data and Anas platyrhynchos genome; Table S3 The five up- and down-regulated genes among the comparison samples; Table S4 Number of differentially expressed genes annotated; Figure S1 Volcano plot figure of DEGs in breast muscle; Figure S2 Volcano plot figure of DEGs in leg muscle; Figure S3 Volcano plot figure of DEGs in the comparison of breast and leg muscle; Figure S4 Cluster diagram of DEGs in breast muscle; Figure S5 Cluster diagram of DEGs in leg muscle; Figure S6 Cluster diagram of DEGs in the comparison of breast and leg muscle; Figure S7 COG classification results of DEGs in breast muscle; Figure S8 COG classification results of DEGs in leg muscle; Figure S9 COG classification results of DEGs in the comparison of breast and leg muscle; Figure S10 Signal pathway of focal adhesion; Figure S11 Signal pathway of MAPK; Figure S12 Signal pathway of regulation of the actin cytoskeleton.

Author Contributions: Z.H. and X.L. conceived the experiments. Z.H. designed the experiments, analyzed the results and wrote the manuscript. J.C. was involved in the data interpretation and writing. H.Z. contributed reagent and materials. G.L. performed sample analysis. All authors have read and agreed to the published version of the manuscript.

Funding: This study was supported by funds from the National Waterfowl Industrial Technology System of China (CARS-42-2) and the Research on the Effect of New Breeding of the Black Muscovy Duck of Shaanxi (2019QYPY-130).

Conflicts of Interest: The authors declare no conflict of interest. 
Availability of Data and Materials: The datasets generated for this study can be found in the NCBI SRA (Submission: SUB8199414 and SUB8199659). Bioproject \#PRJNA665025 and Biosamples \#SAMN16238613-SAMN 16238630, Bioproject \#PRJNA665027 and Biosamples \#SAMN16238633-SAMN16238650.

\section{References}

1. Güller, I.; Russell, A.P. MicroRNAs in skeletal muscle: Their role and regulation in development, disease and function. J. Physiol. 2010, 588, 4075-4087. [CrossRef] [PubMed]

2. Bi, P.; Ramirez-Martinez, A.; Li, H.; Cannavino, J.; McAnally, J.R.; Shelton, J.M.; Sánchez-Ortiz, E.; Bassel-Duby, R.; Olson, E.N. Control of muscle formation by the fusogenic micropeptide myomixer. Science 2017, 356, 323-327. [CrossRef] [PubMed]

3. Mitchell, P.O.; Mills, S.T.; Pavlath, G.K. Calcineurin differentially regulates maintenance and growth of phenotypically distinct muscles. Am. J. Physiol. Physiol. 2002, 282, C984-C992. [CrossRef] [PubMed]

4. Deries, M.; Thorsteinsdóttir, S. Axial and limb muscle development: Dialogue with the neighbourhood. Cell. Mol. Life Sci. 2016, 73, 4415-4431. [CrossRef]

5. Scaal, M.; Marcelle, C. Chick muscle development. Int. J. Dev. Biol. 2018, 62, 127-136. [CrossRef]

6. Buckingham, M.; Bajard, L.; Chang, T.; Daubas, P.; Hadchouel, J.; Meilhac, S.M.; Montarras, D.; Rocancourt, D.; Relaix, F. The formation of skeletal muscle: From somite to limb. J. Anat. 2003, 202, 59-68. [CrossRef]

7. Guo, B.; Greenwood, P.L.; Cafe, L.M.; Zhou, G.; Zhang, W.; Dalrymple, B.P. Transcriptome analysis of cattle muscle identifies potential markers for skeletal muscle growth rate and major cell types. BMC Genom. 2015, 16, 177. [CrossRef]

8. Hutton, K.C.; Vaughn, M.A.; Litta, G.; Turner, B.J.; Starkey, J.D. Effect of vitamin D status improvement with 25-hydroxycholecalciferol on skeletal muscle growth characteristics and satellite cell activity in broiler chickens1,2. J. Anim. Sci. 2014, 92, 3291-3299. [CrossRef]

9. Costa, V.; Angelini, C.; De Feis, I.; Ciccodicola, A. Uncovering the Complexity of Transcriptomes with RNA-Seq. J. Biomed. Biotechnol. 2010, 2010, 1-19. [CrossRef]

10. Waern, K.; Nagalakshmi, U.; Snyder, M. RNA sequencing. Methods Mol. Biol. 2011, 759, 125.

11. Trapnell, C.; Roberts, A.; Goff, L.; Pertea, G.; Kim, D.; Kelley, D.R.; Pimentel, H.; Salzberg, S.L.; Rinn, J.L.; Pachter, L. Differential gene and transcript expression analysis of RNA-seq experiments with TopHat and Cufflinks. Nat. Protoc. 2012, 7, 562-578. [CrossRef] [PubMed]

12. Kumar, D.; Bansal, G.; Narang, A.; Basak, T.; Abbas, T.; Dash, D. Integrating transcriptome and proteome profiling: Strategies and applications. Proteomics 2016, 16, 2533-2544. [CrossRef] [PubMed]

13. Xue, Q.; Zhang, G.; Li, T.; Ling, J.; Zhang, X.; Wang, J. Transcriptomic profile of leg muscle during early growth in chicken. PLoS ONE 2017, 12, e0173824. [CrossRef] [PubMed]

14. Zhang, Z.; Du, H.; Yang, C.; Li, Q.; Qiu, M.; Song, X.; Yu, C.; Jiang, X.; Liu, L.; Hu, C.; et al. Comparative transcriptome analysis reveals regulators mediating breast muscle growth and development in three chicken breeds. Anim. Biotechnol. 2019, 30, 233-241. [CrossRef]

15. Xu, T.-S.; Gu, L.-H.; Huang, W.; Xia, W.-L.; Zhang, Y.-S.; Zhang, Y.-G.; Rong, G.; Schachtschneider, K.M.; Hou, S.-S. Gene expression profiling in Pekin duck embryonic breast muscle. PLoS ONE 2017, 12, e0174612. [CrossRef]

16. Zhu, C.; Song, W.; Tao, Z.; Liu, H.; Xu, W.; Zhang, S.; Li, H. Deep RNA sequencing of pectoralis muscle transcriptomes during late-term embryonic to neonatal development in indigenous Chinese duck breeds. PLoS ONE 2017, 12, e0180403. [CrossRef]

17. Liu, H.X.; Hu, Y.; Ji, G.G.; Li, H.F. Rapid-Sexing Poultries via a New Pair of Universal Primers. J. Agr. Biotechnol. 2014, 22, 1567-1574. (In Chinese)

18. Mutz, K.-O.; Heilkenbrinker, A.; Lönne, M.; Walter, J.-G.; Stahl, F. Transcriptome analysis using next-generation sequencing. Curr. Opin. Biotechnol. 2013, 24, 22-30. [CrossRef]

19. Adiconis, X.; Borges-Rivera, D.; Satija, R.; DeLuca, D.S.; Busby, M.A.; Berlin, A.M.; Sivachenko, A.; Thompson, D.A.; Wysoker, A.; Fennell, T.; et al. Comparative analysis of RNA sequencing methods for degraded or low-input samples. Nat. Methods 2013, 10, 623-629. [CrossRef]

20. Bihan-Duval, E.L.; Millet, N.; Remignon, H. Broiler meat quality: Effect of selection for increased carcass quality and estimates of genetic parameters. Poult. Sci. 1999, 78, 822-826. [CrossRef] 
21. Sachidanandam, R.; Weissman, D.; Schmidt, S.C.; Kakol, J.M.; Stein, L.D.; Marth, G.; Sherry, S.; Mullikin, J.C.; Mortimore, B.J.; Willey, D.L.; et al. A map of human genome sequence variation containing 1.42 million single nucleotide polymorphisms. Nature 2001, 409, 928-933.

22. Huang, Y.; Zou, Y.; He, H.; Dang, Y.-L.; Qi, X.-S.; Chen, H.; Lin, Q.; Zheng, L.; Zhang, Z.-J.; Lei, C.; et al. Effects of genetic variants of the bovine WNT8A gene on nine important growth traits in beef cattle. J. Genet. 2017, 96, 535-544. [CrossRef]

23. Wu, S.; Wang, Y.; Ning, Y.; Guo, H.; Xiaoyu, W.; Zhang, L.; Khan, R.; Cheng, G.; Wang, H.; Zan, L.S. Genetic Variants in STAT3 Promoter Regions and Their Application in Molecular Breeding for Body Size Traits in Qinchuan Cattle. Int. J. Mol. Sci. 2018, 19, 1035. [CrossRef]

24. Sun, Z.; Bhagwate, A.; Prodduturi, N.; Yang, P.; Kocher, J.-P.A. Indel detection from RNA-seq data: Tool evaluation and strategies for accurate detection of actionable mutations. Brief. Bioinform. 2017, 18, 973-983. [CrossRef]

25. Yang, R.; Van Etten, J.L.; Dehm, S.M. Indel detection from DNA and RNA sequencing data with transIndel. BMC Genom. 2018, 19, 1-11. [CrossRef]

26. Chen, L.; Tovar-Corona, J.M.; Urrutia, A.O. Alternative Splicing: A Potential Source of Functional Innovation in the Eukaryotic Genome. Int. J. Evol. Biol. 2012, 2012, 1-10. [CrossRef] [PubMed]

27. Kornblihtt, A.R.; Schor, I.E.; Alló, M.; Dujardin, G.; Petrillo, E.; Muñoz, M.J. Alternative splicing: A pivotal step between eukaryotic transcription and translation. Nat. Rev. Mol. Cell Biol. 2013, 14, 153-165. [CrossRef] [PubMed]

28. Traunmuller, L.; Gomez, A.M.; Nguyen, T.M.; Scheifele, P. Control of neuronal synapse specifcation by a highly dedicated alternative splicing program. Science 2016, 352, 982-986. [CrossRef]

29. Schwerk, C.; Schulze-Osthoff, K. Regulation of Apoptosis by Alternative Pre-mRNA Splicing. Mol. Cell 2005, 19, 1-13. [CrossRef] [PubMed]

30. Thorsteinsdóttir, S.; Roelen, B.A.J.; Goumans, M.-J.; Oostwaard, D.W.-V.; Gaspar, A.C.; Mummery, C. Expression of the $\alpha 6 \mathrm{~A}$ integrin splice variant in developing mouse embryonic stem cell aggregates and correlation with cardiac muscle differentiation. Differentiation 1999, 64, 173. [CrossRef]

31. Schmucker, D.; Clemens, J.C.; Shu,H.; Worby, C.; Xiao, J.; Muda, M.; Dixon, J.E.; Zipursky, S. Drosophila Dscam Is an Axon Guidance Receptor Exhibiting Extraordinary Molecular Diversity. Cell 2000, 101, 671-684. [CrossRef]

32. Gueroussov, S.; Gonatopoulos-Pournatzis, T.; Irimia, M.; Raj, B.; Lin, Z.-Y.; Gingras, A.; Blencowe, B.J. An alternative splicing event amplifies evolutionary differences between vertebrates. Science 2015, 349, 868-873. [CrossRef]

33. Yin, Z.; Zhang, F.; Smith, J.; Kuo, R.; Hou, Z.-C. Full-length transcriptome sequencing from multiple tissues of duck, Anas platyrhynchos. Sci. Data 2019, 6, 1-9. [CrossRef]

34. Park, M.Y.; Jang, H.D.; Lee, S.Y.; Lee, K.J.; Kim, E. Fas-associated factor-1 inhibits nuclear factor-kappaB (NF-kappaB) activity by interfering with nuclear translocation of the RelA (p65) subunit of NF-kappaB. J. Biol. Chem. 2004, 279, 2544-2549. [CrossRef]

35. Park, M.Y.; Moon, J.H.; Lee, K.S.; Choi, H.I.; Chung, J.; Hong, H.J.; Kim, E. FAF1 suppresses IkappaB kinase (IKK) activation by disrupting the IKK complex assembly. J. Biol. Chem. 2007, 282, 27572-27577. [CrossRef] [PubMed]

36. Menges, C.W.; Altomare, D.A.; Testa, J.R. FAS-associated factor 1 (FAF1): Diverse functions and implications for oncogenesis. Cell Cycle 2009, 8, 2528-2534. [CrossRef] [PubMed]

37. Song, E.J.; Yim, S.-H.; Kim, E.; Kim, N.-S.; Lee, K.J. Human Fas-Associated Factor 1, Interacting with Ubiquitinated Proteins and Valosin-Containing Protein, Is Involved in the Ubiquitin-Proteasome Pathway. Mol. Cell. Biol. 2005, 25, 2511-2524. [CrossRef] [PubMed]

38. Jang, M.-S.; Sul, J.-W.; Choi, B.-J.; Lee, S.-J.; Suh, J.-H.; Kim, N.-S.; Kim, W.H.; Lim, D.-S.; Lee, C.-W.; Kim, E.-H. Negative Feedback Regulation of Aurora-A via Phosphorylation of Fas-associated Factor-1. J. Biol. Chem. 2008, 283, 32344-32351. [CrossRef]

39. Zhang, L.; Zhou, F.; Van Laar, T.; Zhang, J.; van Dam, H.; Dijke, P.T. Fas-associated factor 1 antagonizes Wnt signaling by promoting $\beta$-catenin degradation. Mol. Biol. Cell 2011, 22, 1617-1624. [CrossRef]

40. Steinhart, Z.; Angers, S. Wnt signaling in development and tissue homeostasis. Development 2018, 145, dev146589. [CrossRef]

41. Rudnicki, M.A.; Williams, B.O. Wnt signaling in bone and muscle. Bone 2015, 80, 60-66. [CrossRef] [PubMed] 
42. Adham, I.M.; Khulan, J.; Held, T.; Schmidt, B.; Meyer, B.I.; Meinhardt, A.; Engel, W. Fas-associated factor (FAF1) is required for the early cleavage-stages of mouse embryo. Mol. Hum. Reprod. 2008, 14, 207-213. [CrossRef]

43. Ryu, S.-W.; Chae, S.-K.; Lee, K.J.; Kim, E. Identification and Characterization of Human Fas Associated Factor 1, hFAF1. Biochem. Biophys. Res. Commun. 1999, 262, 388-394. [CrossRef]

44. Fröhlich, T.; Risau, W.; Flamme, I. Characterization of novel nuclear targeting and apoptosis-inducing domains in FAS associated factor 1. J. Cell Sci. 1998, 111, 2353-2363.

45. Siderovski, D.P.; Willard, F.S. The GAPs, GEFs, and GDIs of heterotrimeric G-protein alpha subunits. Int. J. Biol. Sci. 2005, 1, 51-66. [CrossRef] [PubMed]

46. Berman, D.M.; Kozasa, T.; Gilman, A.G. The GTPase-activating Protein RGS4 Stabilizes the Transition State for Nucleotide Hydrolysis. J. Biol. Chem. 1996, 271, 27209-27212. [CrossRef]

47. Sjögren, B.; Blazer, L.L.; Neubig, R.R. Regulators of G Protein Signaling Proteins as Targets for Drug Discovery. Prog. Mol. Biol. Transl. Sci. 2010, 91, 81-119. [CrossRef]

48. Benians, A.; Nobles, M.; Hosny, S.; Tinker, A. Regulators of G-protein Signaling Form a Quaternary Complex with the Agonist, Receptor, and G-protein. J. Biol. Chem. 2005, 280, 13383-13394. [CrossRef]

49. Bansal, G.; Druey, K.M.; Xie, Z. R4 RGS proteins: Regulation of G-protein signaling and beyond. Pharmacol. Ther. 2007, 116, 473-495. [CrossRef] [PubMed]

50. De Vries, L. RGS proteins: More than just GAPs for heterotrimeric G proteins. Trends Cell Biol. 1999, 9, $138-144$. [CrossRef]

51. Yu, Y.; Yoon, S.-O.; Poulogiannis, G.; Yang, Q.; Ma, X.M.; Villén, J.; Kubica, N.; Hoffman, G.R.; Cantley, L.C.; Gygi, S.P.; et al. Phosphoproteomic Analysis Identifies Grb10 as an mTORC1 Substrate That Negatively Regulates Insulin Signaling. Science 2011, 332, 1322-1326. [CrossRef] [PubMed]

52. Liu, B.; Liu, F. Feedback regulation of mTORC1 by Grb10 in metabolism and beyond. Cell Cycle 2014, 13, 2643-2644. [CrossRef]

53. Smith, F.M.; Holt, L.J.; Garfield, A.S.; Charalambous, M.; Koumanov, F.; Perry, M.; Bazzani, R.; Sheardown, S.A.; Hegarty, B.D.; Lyons, R.J.; et al. Mice with a Disruption of the Imprinted Grb10 Gene Exhibit Altered Body Composition, Glucose Homeostasis, and Insulin Signaling during Postnatal Life. Mol. Cell. Biol. 2007, 27, 5871-5886. [CrossRef] [PubMed]

54. Deng, Y.; Zhang, M.; Riedel, H. Mitogenic roles of Gab1 and Grb10 as direct cellular partners in the regulation of MAP kinase signaling. J. Cell. Biochem. 2008, 105, 1172-1182. [CrossRef]

55. Holt, L.J.; Siddle, K. Grb10 and Grb14: Enigmatic regulators of insulin action-and more? Biochem. J. 2005, 388, 393-406. [CrossRef]

56. Desbuquois, B.; Carré, N.; Burnol, A.F. Regulation of insulin and type 1 insulin-like growth factor signaling and action by the Grb10/14 and SH2B1/B2 adaptor proteins. FEBS J. 2013, 280, 794-816. [CrossRef]

57. Jahn, T.; Seipel, P.; Urschel, S.; Peschel, C.; Duyster, J. Role for the Adaptor Protein Grb10 in the Activation of Akt. Mol. Cell. Biol. 2002, 22, 979-991. [CrossRef]

58. Langlais, P.; Dong, L.Q.; Ramos, F.J.; Hu, D.; Li, Y.; Quon, M.J.; Liu, F. Negative Regulation of Insulin-Stimulated Mitogen-Activated Protein Kinase Signaling By Grb10. Mol. Endocrinol. 2004, 18, 350-358. [CrossRef] [PubMed]

59. Monami, G.; Emiliozzi, V.; Morrione, A. Grb10/Nedd4-mediated multiubiquitination of the insulin-like growth factor receptor regulates receptor internalization. J. Cell Physiol. 2008, 216, 426-437. [CrossRef] [PubMed]

60. Wang, L.; Balas, B.; Christ-Roberts, C.Y.; Kim, R.Y.; Ramos, F.J.; Kikani, C.K.; Li, C.; Deng, C.; Reyna, S.; Musi, N.; et al. Peripheral Disruption of the Grb10 Gene Enhances Insulin Signaling and Sensitivity In Vivo. Mol. Cell. Biol. 2007, 27, 6497-6505. [CrossRef]

61. Verbrugge, S.A.J.; Schönfelder, M.; Becker, L.; Nezhad, F.Y.; De Angelis, M.H.; Wackerhage, H. Genes Whose Gain or Loss-Of-Function Increases Skeletal Muscle Mass in Mice: A Systematic Literature Review. Front. Physiol. 2018, 9, 553. [CrossRef] [PubMed]

62. Du, S.J.; Tan, X.; Zhang, J. SMYD Proteins: Key Regulators in Skeletal and Cardiac Muscle Development and Function. Anat. Rec. Adv. Integr. Anat. Evol. Biol. 2014, 297, 1650-1662. [CrossRef] [PubMed]

63. Kristin, L.; Mark, B. SET/MYND Lysine Methyltransferases Regulate Gene Transcription and Protein Activity. Genes 2011, 2, 210-218. 
64. Fujii, T.; Tsunesumi, S.I.; Yamaguchi, K.; Watanabe, S.; Furukawa, Y. Smyd3 Is Required for the Development of Cardiac and Skeletal Muscle in Zebrafish. PLoS ONE 2011, 6, e23491. [CrossRef]

65. Tracy, C.M.; Warren, J.S.; Szulik, M.; Wang, L.; Garcia, J.; Makaju, A.; Russell, K.; Miller, M.; Franklin, S. The Smyd family of methyltransferases: Role in cardiac and skeletal muscle physiology and pathology. Curr. Opin. Physiol. 2018, 1, 140-152. [CrossRef]

66. Proserpio, V.; Fittipaldi, R.; Ryall, J.G.; Sartorelli, V.; Caretti, G. The methyltransferase SMYD3 mediates the recruitment of transcriptional cofactors at the myostatin and c-Met genes and regulates skeletal muscle atrophy. Genes Dev. 2013, 27, 1299-1312. [CrossRef]

67. Palstra, A.P.; Tudorache, C.; Rovira, M.; Brittijn, S.A.; Burgerhout, E.; Thillart, G.E.E.J.M.V.D.; Spaink, H.P.; Planas, J.V. Establishing Zebrafish as a Novel Exercise Model: Swimming Economy, Swimming-Enhanced Growth and Muscle Growth Marker Gene Expression. PLOS ONE 2010, 5, e14483. [CrossRef] [PubMed]

68. Zhang, L.; Zhou, Y.; Wu, W.; Hou, L.; Chen, H.; Zuo, B.; Xiong, Y.; Yang, J. Skeletal Muscle-Specific Overexpression of PGC-1 $\alpha$ Induces Fiber-Type Conversion through Enhanced Mitochondrial Respiration and Fatty Acid Oxidation in Mice and Pigs. Int. J. Biol. Sci. 2017, 13, 1152-1162. [CrossRef]

69. Barton, P.J.R.; Townsend, P.J.; Brand, N.J.; Yacoub, M.H. Localization of the fast skeletal muscle troponin I gene (TNNI2) to 11p15.5: Genes for troponin I and T are organized in pairs. Ann. Hum. Genet. 1997, 61, 519-523. [CrossRef]

70. Sheng, J.-J.; Jin, J.-P. TNNI1, TNNI2 and TNNI3: Evolution, regulation, and protein structure-function relationships. Gene 2016, 576, 385-394. [CrossRef] [PubMed]

71. Zhu, X.; Wang, F.; Zhao, Y.; Yang, P.; Chen, J.; Sun, H.; Liu, L.; Li, W.; Pan, L.; Guo, Y.; et al. A Gain-of-Function Mutation in Tnni2 Impeded Bone Development through Increasing Hif3a Expression in DA2B Mice. PLoS Genet. 2014, 10, e1004589. [CrossRef] [PubMed]

72. Farah, C.S.; Miyamoto, C.; Ramos, C.H.; Da Silva, A.C.; Quaggio, R.B.; Fujimori, K.; Smillie, L.B.; Reinach, F.C. Structural and regulatory functions of the $\mathrm{NH} 2-$ and $\mathrm{COOH}$-terminal regions of skeletal muscle troponin I. J. Biol. Chem. 1994, 269, 5230-5240.

73. Yoshimoto, Y.; Ikemoto-Uezumi, M.; Hitachi, K.; Fukada, S.-I.; Uezumi, A. Methods for Accurate Assessment of Myofiber Maturity During Skeletal Muscle Regeneration. Front. Cell Dev. Biol. 2020, 8, 267. [CrossRef]

74. Vigoreaux, J.O. Genetics of theDrosophila flight muscle myofibril: A window into the biology of complex systems. BioEssays 2001, 23, 1047-1063. [CrossRef] [PubMed]

75. Zhu, L.; Lyons, G.E.; Juhasz, O.; Joya, J.E.; Hardeman, E.C.; Wade, R. Developmental Regulation of Troponin I Isoform Genes in Striated Muscles of Transgenic Mice. Dev. Biol. 1995, 169, 487-503. [CrossRef]

76. Duperret, E.K.; Ridky, T.W. Focal adhesion complex proteins in epidermis and squamous cell carcinoma. Cell Cycle 2013, 12, 3272-3285. [CrossRef]

77. Graham, Z.A.; Gallagher, P.M.; Cardozo, C.P. Focal adhesion kinase and its role in skeletal muscle. J. Muscle Res. Cell Motil. 2015, 36, 305-315. [CrossRef]

78. Wagner, E.F.; Nebreda, Á.R. Signal integration by JNK and p38 MAPK pathways in cancer development. Nat. Rev. Cancer 2009, 9, 537-549. [CrossRef] [PubMed]

79. Ito, N.; Ruegg, U.T.; Takeda, S. ATP-Induced Increase in Intracellular Calcium Levels and Subsequent Activation of mTOR as Regulators of Skeletal Muscle Hypertrophy. Int. J. Mol. Sci. 2018, 19, 2804. [CrossRef]

80. Desmarais, V.; Ghosh, M.; Eddy, R.; Condeelis, J.S. Cofilin takes the lead. J. Cell Sci. 2004, 118, $19-26$. [CrossRef] [PubMed]

81. Le Clainche, C.; Carlier, M.-F. Regulation of Actin Assembly Associated With Protrusion and Adhesion in Cell Migration. Physiol. Rev. 2008, 88, 489-513. [CrossRef] [PubMed]

82. Tang, D.D.; Gerlach, B.D. The roles and regulation of the actin cytoskeleton, intermediate filaments and microtubules in smooth muscle cell migration. Respir. Res. 2017, 18,1-12. [CrossRef] [PubMed]

Publisher's Note: MDPI stays neutral with regard to jurisdictional claims in published maps and institutional affiliations. 